\title{
Targeting Glucose Metabolism to Overcome Resistance to Anticancer Chemotherapy in Breast Cancer
}

\author{
Elizabeth Varghese ${ }^{1}$, Samson Mathews Samuel ${ }^{1}{ }^{\mathbb{D}}$, Alena Líšková ${ }^{2}$, Marek Samec $^{2}$, \\ Peter Kubatka $^{3} \mathbb{D}$ and Dietrich Büsselberg ${ }^{1, * \mathbb{D}}$ \\ 1 Department of Physiology and Biophysics, Weill Cornell Medicine-Qatar, Education City, Qatar Foundation, \\ Doha 24144, Qatar; elv2007@qatar-med.cornell.edu (E.V.); sms2016@qatar-med.cornell.edu (S.M.S.) \\ 2 Department of Obstetrics and Gynecology, Jessenius Faculty of Medicine, Comenius University in Bratislava, \\ 03601 Martin, Slovakia; liskova80@uniba.sk (A.L.); marek.samec@gmail.com (M.S.) \\ 3 Department of Medical Biology, Jessenius Faculty of Medicine, Comenius University in Bratislava, \\ 03601 Martin, Slovakia; peter.kubatka@uniba.sk \\ * Correspondence: dib2015@qatar-med.cornell.edu; Tel.: +974-4492-8334; Fax: +974-4492-8333
}

Received: 21 June 2020; Accepted: 6 August 2020; Published: 12 August 2020

check for updates

\begin{abstract}
Breast cancer $(\mathrm{BC})$ is the most prevalent cancer in women. BC is heterogeneous, with distinct phenotypical and morphological characteristics. These are based on their gene expression profiles, which divide BC into different subtypes, among which the triple-negative breast cancer (TNBC) subtype is the most aggressive one. The growing interest in tumor metabolism emphasizes the role of altered glucose metabolism in driving cancer progression, response to cancer treatment, and its distinct role in therapy resistance. Alterations in glucose metabolism are characterized by increased uptake of glucose, hyperactivated glycolysis, decreased oxidative phosphorylation (OXPHOS) component, and the accumulation of lactate. These deviations are attributed to the upregulation of key glycolytic enzymes and transporters of the glucose metabolic pathway. Key glycolytic enzymes such as hexokinase, lactate dehydrogenase, and enolase are upregulated, thereby conferring resistance towards drugs such as cisplatin, paclitaxel, tamoxifen, and doxorubicin. Besides, drug efflux and detoxification are two energy-dependent mechanisms contributing to resistance. The emergence of resistance to chemotherapy can occur at an early or later stage of the treatment, thus limiting the success and outcome of the therapy. Therefore, understanding the aberrant glucose metabolism in tumors and its link in conferring therapy resistance is essential. Using combinatory treatment with metabolic inhibitors, for example, 2-deoxy-D-glucose (2-DG) and metformin, showed promising results in countering therapy resistance. Newer drug designs such as drugs conjugated to sugars or peptides that utilize the enhanced expression of tumor cell glucose transporters offer selective and efficient drug delivery to cancer cells with less toxicity to healthy cells. Last but not least, naturally occurring compounds of plants defined as phytochemicals manifest a promising approach for the eradication of cancer cells via suppression of essential enzymes or other compartments associated with glycolysis. Their benefits for human health open new opportunities in therapeutic intervention, either alone or in combination with chemotherapeutic drugs. Importantly, phytochemicals as efficacious instruments of anticancer therapy can suppress events leading to chemoresistance of cancer cells. Here, we review the current knowledge of altered glucose metabolism in contributing to resistance to classical anticancer drugs in BC treatment and various ways to target the aberrant metabolism that will serve as a promising strategy for chemosensitizing tumors and overcoming resistance in BC.
\end{abstract}


Keywords: anticancer drug; breast cancer; cancer; chemoresistance; glucose metabolism; resistance; sensitization; triple-negative breast cancer

\section{Introduction}

Breast cancer (BC) is the most prevalent type of cancer seen in women. Worldwide statistics show that in 2018 approximately two million new cases were detected, with total BC accounting for $11.6 \%$ of all cancers [1,2], even though various awareness programs and modern diagnostics increased detection at an early stage. Unfortunately, the majority of BC cases are still detected in later stages as the early stages are often asymptomatic; patients often ignore telltale signs of the disease and avoid screening programs. Depending upon the severity of cancer, treatment modalities include surgery, radiation therapy, chemotherapy, immunotherapy, and targeted therapy [3].

Chemotherapeutic drugs are administered to patients before surgery (as neoadjuvant therapy) or post-surgery (as adjuvant therapy) and are primarily aimed at selective inhibiting the proliferation and activating apoptosis in cancer cells. However, very often, patients encounter moderate to severe side effects in addition to developing acquired resistance to the drug (which is a more adaptive response to the presence of drug) due to prolonged treatment [4,5]. In addition to acquired drug resistance, several other factors contribute to treatment resistance, and variations in the pattern of resistance are observed between different cancers and anticancer drugs [6]. In BC, the response to chemotherapeutic drugs varies with the different BC-subtypes, which, to a certain degree, is attributed to their heterogeneity. Additionally, specific genetic, epigenetic, and metabolic attributes of the subtypes confer an in-built resistance (intrinsic resistance due to gene mutations) against certain drugs [7]. Therefore, changes in the tumor environment, the methylation status of genes, and altered tumor metabolism continually churns out a new subset of cells that keep the tumor advancing in growth and spread [7].

The study of the metabolic characteristics of the tumor and their link to cancer progression is an emerging field in cancer research. Metabolic plasticity in tumors is not only contributed by glycolytic phenotype (as explained by Warburg), but recently mitochondrial energy reprogramming has been identified as a characteristic of the tumor to meet the high demand for energy and biomolecule precursors for rapid cancer cell proliferation. Therefore, recent research emphasizes a hybrid glycolysis/OXPHOS (oxidative phosphorylation) phenotype, rather than a phenotype overly dependent on glycolysis for the energy needs of the cell, thereby significantly contributing to aggressiveness and therapy resistance [8]. The regulation of tumor metabolism as a therapeutic strategy holds promise for any type of cancer, including BC. Vital differences/alterations in glucose metabolism exist between the sensitive and resistant phenotypes of $\mathrm{BC}$ [9]. Cancer cells rely on higher rates of aerobic glycolysis as their primary source of energy, even in the presence of oxygen (known as Warburg effect) [10], thus promoting cancer cell proliferation, cancer progression, and resistance to apoptotic cell death [11]. This aberrant tumor glucose metabolism and the increased rates of glycolysis in tumors are correlated to intrinsic/acquired resistance to routinely used anticancer drugs [11-13]. In this review, we focus on various ways to target the aberrant metabolism that should serve as a promising strategy for chemosensitizing tumors and overcoming resistance in $\mathrm{BC}$, thus effectively treating $\mathrm{BC}$ with minimal side-effects and blocking invasion, metastasis, and incidence of recurrence in affected individuals. 


\section{Altered Glucose Metabolism in Different Subtypes of BC}

Originally, BC was broadly classified into hormone receptor-positive $\mathrm{BC}$ and hormone receptornegative, but with the advancement in diagnostics and molecular biology, a more complex and heterogeneous nature of $\mathrm{BC}$ was revealed [14]. Heterogeneity varies from patient to patient (inter-tumor) or exists as heterogeneity within the tumor itself (intra-tumor) [15]. The latter defines differences in the cellular, molecular, and metabolic characteristics of the tumor. Identifying molecular subtypes is a major step towards the selection of the treatment strategy and prediction of the treatment outcome. Based on the presence or absence of the estrogen receptor (ER), progesterone receptor (PR), human epidermal growth factor receptor 2 (HER2), and Ki-67 status, BCs are classified as HER2+ (ER-, PR-, HER2 overexpressed), luminal A (ER+,PR+, HER2-, Ki 67 low), luminal B (ER+, PR low, HER2-, Ki 67 high), and basal/triple-negative (ER-,PR-, HER2-) subtypes [16]. Invasive BC, which is positive for either one or more of the three important biomarkers ER, PR, and HER2, can be targeted by hormone-based therapy, whereas tumors that are negative for all three receptors, classified as triple-negative breast cancers (TNBC), do not benefit from hormone-based therapy. Six subtypes of TNBCs were identified using gene expression analysis: Basal-like 1 (BL1), Basal-like 2 (BL2), Mesenchymal (M), Mesenchymal stem-like (MSL), immunomodulatory (IM), and luminal androgen receptor (LAR). This reveals the complexity of the treatment of TNBC $[14,17,18]$. Hitherto, there are no effective targeted drugs identified, and systemic treatment with cytotoxic agents remains the standard therapeutic strategy.

Identifying metabolic differences among BC molecular subtypes helps to fine-tune strategies to target specific enzymes and transporters. Metabolomic studies expand the scope of tumor classification beyond the present molecular subtypes and add value to clinical trials. Cappelletti V. et al. [19] reported metabolic differences among BC subtypes in patients with primary BC undergoing surgery. Significant differences in the enzyme activity and pathways were reported for glucose metabolism [19]. The higher glycolytic potential is frequently linked to therapeutic resistance [20]. There were considerable metabolic differences among HER2+, luminal A, and luminal B subtypes [21]. Perturbations in glucose metabolism were more prominent in the HER2+ BC and the luminal B subtype. Although the level of glucose utilization was the same among the three subtypes, the accumulation of metabolites in the downstream glycolytic pathway was higher in luminal B, basal-like, and HER2+ than in luminal A [19].

The increased reliance of cancer cells on aerobic glycolysis, although less efficient in generating ATP, not only meets the energy requirements of the rapidly proliferating cancer cells, but also suffices the higher demand for metabolic intermediates required for anabolic reactions [22,23]. Glycolytic intermediates form the carbon backbone for the biosynthesis of nucleotides, amino acids, and lipids [22,23]. The glycolytic intermediate glucose-6-phosphate is channeled to the pentose phosphate pathway and converted to ribose-5-phosphate, which is then used for nucleotide biosynthesis [23,24]. The dihydroxyacetone phosphate (DHAP), another intermediate in the glycolytic pathway, fuels the de novo synthesis of lipid in addition to the mitochondrial tricarboxylic acid cycle (TCA) intermediates, such as acetyl coenzyme A (Acetyl CoA) which further supports lipid and cholesterol synthesis [22,24]. Cellular lipogenesis is essential for membrane biogenesis and hence high rate of lipogenesis is indicated in rapidly proliferating tumor cells [25]. Additionally, the glycolytic intermediate 3-phosphogycerate is a precursor for amino acid and nucleotide biosynthetic pathways [24,26]. Looking at the metabolite status from the clinical point of view a significant difference in the lactate levels was observed with basal-like subtype having more lactate than luminal A subtype. Similarly, high levels of fructose 1,6 bisphosphate (F1,6BP) were reported in the basal-like subtype of BC. Ribulose 5-phosphate and xylulose 5-phosphate of the pentose phosphate pathway (PPP) are accumulated in HER2+ BC [19]. Analysis of the TCA metabolites did not show significant differences, except for the fumarate and malate levels [19]. These metabolites can fuel fatty acid biosynthesis and cholesterol synthesis, thereby promoting tumor growth [27]. Abnormally high levels of fumarate and succinate were showed to stabilize hypoxia inducible factor 1-alpha (HIF-1 $\alpha$ ) and related genes and created a pseudo-hypoxic condition in tumors promoting angiogenesis, migration, and metastasis [28]. Moreover, these metabolites change the 
epigenetic profile of the cells as well [28]. Similarly, 3-phosphoglycerate, a glycolytic intermediate, fuels the de novo biosynthesis of serine and one of the enzymes, phosphoglycerate dehydrogenase (PHGDH), which catalyzes this process and is highly expressed in TNBCs [28]. An in-depth review by Amelio I. and co-workers [29] mentions serine as an allosteric modulator of glycolytic enzyme pyruvate kinase M2 isoform (PKM2). High serine levels can fully activate the PKM2 enzyme driving the cell to a more aerobic glycolysis process and lactate production. Conversely, upon serine depletion, PKM2 activity is reduced, as a result the cells switch to mitochondrial mode of metabolism. Serine is also linked to other metabolic pathways such as glycine metabolism, which has a significant role in tumorigenesis [29]. High rates of glycolysis and the associated poor prognosis in BCs were linked to an increased level of lipogenesis, marked by the overexpression of key fatty acid synthesis enzymes such as ATP citrate lyase, acetyl CoA carboxylase, and fatty acid synthase [30,31].

The enzyme succinate dehydrogenase (SDH; composed of the four subunits: SDHA, SDHB, SDHC, and SDHD), catalyzing succinate oxidation in TCA, was differently expressed in BC subtypes. A higher level of SDHA and SDHB was detected in HER-2 subtype. On the contrary, lower or absent expression of SDHA and SDHB was documented in Luminal A and TNBC, respectively. Moreover, it was observed that the lower expression profile of SDH was more frequent among young patients and patients with low-grade histology [32].

Metabolic profiling of TNBC in vitro revealed an altered metabolism that links to cell signaling by epidermal growth factor receptor (EGFR) and receptor tyrosine kinase (RTK) [33]. In the TNBC cell line, MDA-MB-468 overexpressing EGFR showed a high rate of glycolysis upon stimulation with epidermal growth factor (EGF). Increased lactate production was found to show dependency on EGF/EGFR signaling and, in fact, EGFR signaling correlated with $\mathrm{T}$ cell inactivity and immune evasion when co-cultured with T cells [33]. Therefore, targeting these signaling pathways could change the metabolic vulnerabilities in TNBC. For example, TNBC is less sensitive to metformin treatment in the presence of high glucose [34].

Similarly, high enolase (EN) and hexokinase (HK) activity are linked to tamoxifen resistance in ER+ BC $[35,36]$. Additionally, HK2 and phosphofructokinase (PFK-L) status indicate the risk of relapse, aggressiveness, and poor prognosis in BC patients [37,38]. A review by Sun $X$ et al. [39] discusses various glycolytic enzymes and other metabolic pathways dysregulated in TNBC and the metabolic adaptations in metastasis and resistance. Earlier observations are in agreement with proteomic profiling of BC cells, revealed that most of the proteins overexpressed belonged to the glycolytic pathway [40].

\section{Glycolytic Pathway Targeted by Classical Anticancer Drugs and Other Compounds}

Enhanced glycolysis correlates with the upregulation and activation of critical glycolytic enzymes, which, in turn, promotes tumorigenesis [41]. Targeting key glycolytic enzymes enables the rewiring of altered tumor metabolism, thereby sensitizing or resensitizing (in case of resistance) tumors to chemotherapy. Many compounds, including natural compounds, influence the tumor microenvironment by regulating HIF- $1 \alpha$ expression and can dysregulate glucose metabolism [42,43]. Selected inhibitors of the transporters, glycolysis, and mitochondrial components are illustrated and summarized in Figure $1 \mathrm{~A}$ and Table 1. 


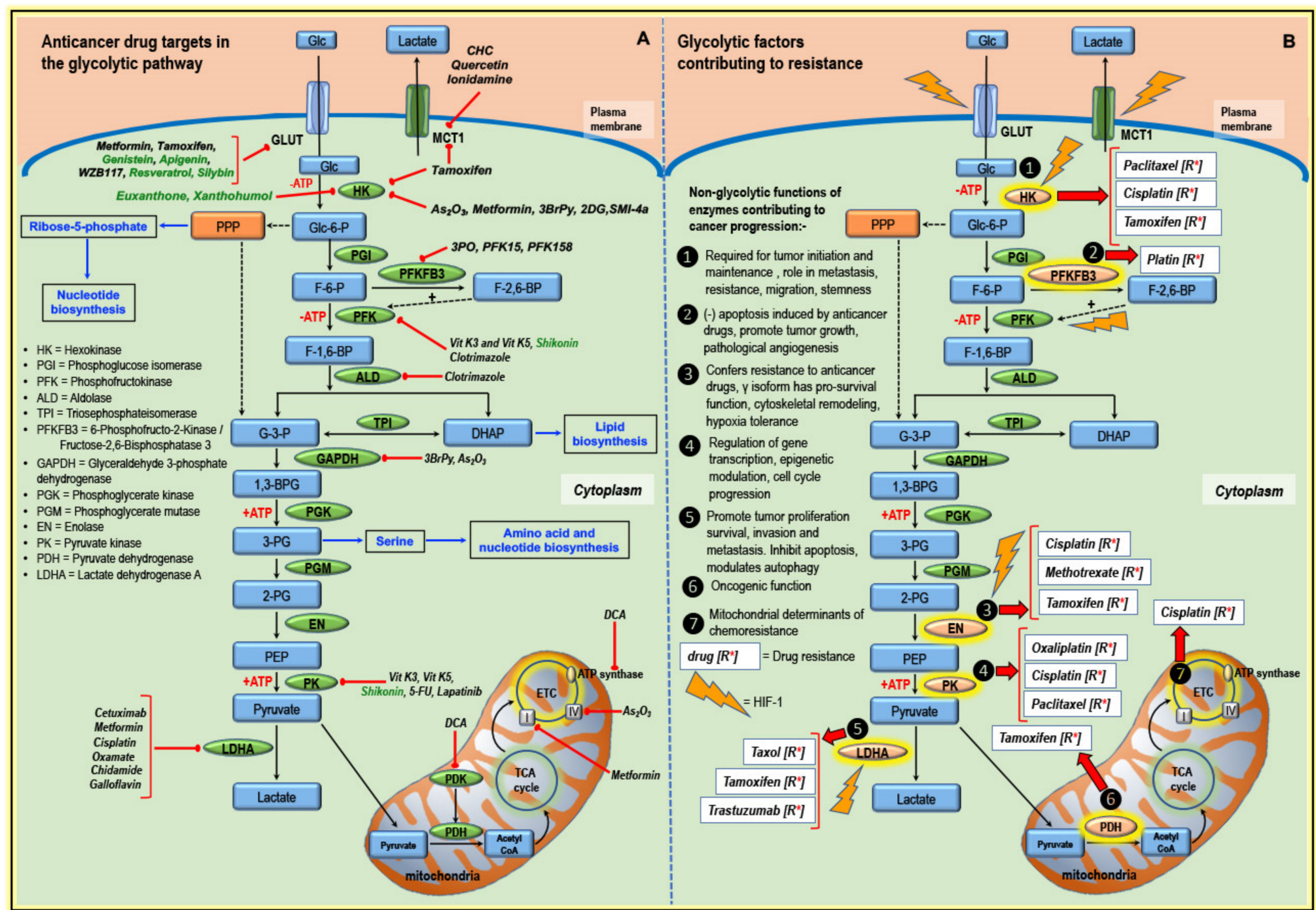

Figure 1. An illustration of glucose metabolism leading from the glycolytic pathway to the tricarboxylic acid cycle (TCA) and electron transport chain (ETC). (A) Targets 
and inhibitors of the glycolytic pathway, TCA, and ETC. These inhibitors target key enzymes/components, thereby regulating glucose metabolism. The bold red lines with rounded ends indicate the inhibitory effect of the various agents on target enzymes/components. Classical anticancer drugs like cisplatin, As ${ }_{2} \mathrm{O}_{3}$, and doxorubicin can modulate glycolytic enzymes. Some natural compounds (shown in the green color font) such as resveratrol, genistein, and shikonin can modify the activity of these enzymes. The blue arrows represent how metabolites of the glycolytic pathway contribute to other key biosynthetic pathways that support cancer cell survival and growth. The precursors for de novo biosynthesis of nucleotides are derived from ribose 5-phosphate of the pentose phosphate pathway (PPP), which is a side branch of glucose metabolic pathway. Likewise, 3-PG, a glycolytic intermediate, serves as a precursor for amino acid synthesis, thus fueling anabolic reactions necessary for cancer growth. Similarly, an enhanced lipogenesis controlled by an oncogenic signaling is often associated with an increased tumor glycolysis. Here, DHAP acts as an intermediate for lipid biosynthesis. (B) The various enzymes/components that contribute to drug resistance in cancers and how the non-glycolytic functions of these enzymes contribute to cancer progression is highlighted. The transcription factor, hypoxia-inducible factor-1 (HIF-1), upregulates the expression of the key transporters and glycolytic enzymes, thereby promoting adaptive cancer cell metabolism and supporting tumor progression. Abbreviations; Glc $=$ glucose, Glc-6-P = glucose-6-phosphate, F-6-P = fructose-6-phosphate, F-1,6-P = fructose 1,6 bisphosphate, G-3-P = glyceraldehyde 3 phosphate, DHAP = dihydroxyacetone phosphate, 1,3-BPG = 1,3-bisphosphoglycerate, 3-PG = 3-phosphoglycerate, 2-PG = 2-phosphoglycerate, $\mathrm{PEP}=$ phosphoenolpyruvate, GLUT = glucose transporter, MCT1 = monocarboxylate transporter 1, SMI-4a = (5Z)-5-[[3-(Trifluoromethyl)phenyl]methylene]-2,4-thiazolidinedione, 3PO = 3-(3-pyridinyl)-1-(4-pyridinyl)-2-propen-1-one, 3BrPy $=3$-bromopyruvate, $2 \mathrm{DG}=2$-deoxy-D-glucose, $\mathrm{DCA}=$ dichloroacetate.

Table 1. A list of glycolytic inhibitors targeting critical enzymes in the glucose metabolic pathway.

\begin{tabular}{|c|c|c|c|c|}
\hline Serial Number & Target & Compounds & Model & Reference \\
\hline 1 & GLUT & $\begin{array}{l}\text { Apigenin, Genistein, Cisplatin, Metformin, Tamoxifen, } \\
\text { EGCG, Hesperetin, Kaempferol, Silybin }\end{array}$ & MCF-7, ZR-75-1, T-47D, MDA-MB-231, 4T1 & {$[42,44-51]$} \\
\hline 2 & $\mathrm{MCT}$ & $\begin{array}{l}\text { Quercetin, } \alpha \text {-cyano-4-hydroxycinnamate } \\
\text { and Lonidamine }\end{array}$ & $\begin{array}{l}\text { MDA-MB-231, MDA-MB-468, MCF-7/AZ, } \\
\text { SKBr3, Hs 578T, BT-20 }\end{array}$ & {$[52,53]$} \\
\hline 3 & HK & Polydatin, 2-DG, Tamoxifen, Metformin, 3-BrPy, EGCG & MDA-MB-231, 4T1 & {$[54,55]$} \\
\hline 4 & PFKFB3 & 3PO, PFK15, PFK158 & SKBR3, BT-474 & {$[56,57]$} \\
\hline 5 & GAPDH & 3-BrPy & HepG2, PC-3 & {$[58,59]$} \\
\hline 6 & PK & $\begin{array}{c}\text { Vit K3, Vit K5, } \\
\text { Shikonin, 5-FU, Lapatinib, EGCG, Quercetin }\end{array}$ & $\begin{array}{l}\text { MDA-MB-231 } \\
\text { MCF-7, 4T1 }\end{array}$ & {$[60,61]$} \\
\hline 7 & $\begin{array}{l}\text { LDHA } \\
\text { LDHB }\end{array}$ & $\begin{array}{c}\text { Cetuximab, Metformin, Oxamate, Chidamide, } \\
\text { Galloflavin } \\
\text { Cisplatin }\end{array}$ & $\begin{array}{l}\text { MBA-MD-231 } \\
\text { MCF-7 }\end{array}$ & {$[46,62-65]$} \\
\hline 8 & Mitochondria & DCA, Metformin, $\mathrm{As}_{2} \mathrm{O}_{3}$ & $\begin{array}{l}\text { T47D, BT-20, MCF-10A, MDA-MB-468, } \\
\text { MDA-MB-231 }\end{array}$ & [66-69] \\
\hline
\end{tabular}

2-DG = 2-deoxyglucose, 3-BrPy = 3-bromopyruvate, 3PO = 3-(3-pyridinyl)-1-(4-pyridinyl)-2-propen-1-one, 5-FU = 5-flurouracil, DCA = dichloroacetate, EGCG = epigallocatechin-3-gallate, $\mathrm{GAPDH}=$ glyceraldehyde-3-phosphate dehydrogenase, GLUT = glucose transporter, $\mathrm{HK}=$ hexokinase, $\mathrm{LDHA} / \mathrm{B}=$ lactate dehydrogenase $\mathrm{A} / \mathrm{B}, \mathrm{MCT}=$ monocarboxylate transporter, PFKFB3 = 6-phosphofructo-2-kinase/fructose-2,6-bisphosphatase 3, PK = pyruvate kinase. 


\subsection{Targeting Transporters}

GLUTs, the glucose transporters in mammalian cells, favor aerobic glycolysis [70]. Increased glucose utilization, activated glycolysis driven by oncogenic signaling to derive energy leading to lactate accumulation in cancer cells can occur even in the presence of oxygen. Concerning the glucose transporters (GLUT-1), the expression was higher in TNBC (basal-like) than in non-TNBC [39]. Frequently, GLUT-1 and GLUT-3 are upregulated in BC cell lines MDA-MB-435 and MDA-MB-231 [71]. Constitutively activated HIF- $1 \alpha$ in cancer cells is associated with an upregulated of GLUT-1 and GLUT-3 expression [72]. Other studies mentioned that immunohistochemical patterns to 18-fluorodeoxyglucose $(18 \mathrm{FdG})$ uptake showed a significant correlation with GLUT-1 expression and HIF-1 $\alpha$ [73]. Several compounds have shown their capability to bind to the different domains of GLUT transporters and thus influence the activity and function of the transporters. For example, genistein binds to the exofacial side of GLUT transporter, whereas quercetin, tyrphostin A47, and tyrphostin B46 bind to the cytoplasmic side of the cell (Table 1) [74,75]. A small molecule inhibitor WZB117 and resveratrol can directly inhibit GLUT-1 transporter [76,77], whereas genistein has been reported to be a competitive inhibitor of GLUT-1 transporter, thus affects transport of hexoses and dehydroascorbic acid. Tamoxifen, a specific ER modulator, widely used in BC treatment, possess an anti-estrogenic effect, which in turn reduce the GLUT-1 expression by two-fold in BC cells (Figure 1A) [44]. Therefore, GLUT-1 is used as a marker for treatment response to tamoxifen [44]. Sawayama H. et al. [78] studied the influence of GLUT-1 inhibition on cisplatin response in esophageal cancer and found that the inhibition of GLUT-1 using miRNAs or specific inhibitors improved the sensitivity to low dose cisplatin treatment $[44,78]$. Metformin, a widely used antidiabetic drug, is also being investigated for its anticancer potential [45]. Metformin can inhibit proliferation and induce apoptosis in BC cells by downregulating all isoforms of GLUT (Figure 1A) [46]. However, metformin is reported to upregulate GLUT-12 in TNBC [46]. Resveratrol, a polyphenol having many bioactivities, has been shown to interact non-competitively with GLUT-1 (Figure 1A) [77]. Furthermore, natural flavonoids, including hesperetin, kaempferol, and epigallocatechin-3-gallate (EGCG), significantly reduced the level of GLUT-1 in BC (4T1, MCF-7, and MDA-MB-231) cell lines [47-49].

The monocarboxylate transporter (MCT) is a lactate efflux transporter, which is essential for maintaining $\mathrm{pH}$ and for regulating glycolysis. MCT 1-4 were biochemically characterized, and MCT1 and MCT4 are often associated with tumors $[79,80]$. Therefore, they are attractive targets for anticancer therapy [81]. As observed in HeLa cells, HIF-1 $\alpha$ under hypoxic conditions increased the expression of MCT4 but did not have any influence on MCT1 expression. It is observed that the physiological function of MCT4 is to transport lactate out of the glycolytic cell [82]. MCT1 primarily deals with pyruvate export and lactate uptake [83]. Studies report an elevated MCT1 expression in aggressive BC with glycolytic phenotype. Inhibition of MCT1 using blockers (in HS578T, SUM149PT, and SUM159PT BC cells) attenuated pyruvate transport but not lactate. Notably, blocking of MCT1 enhanced the oxidative metabolism and parallelly reduced BC cell proliferation [83]. In a tumor microenvironment, MCT pumps lactate to the extracellular space creating an acidic condition favoring cancer progression. Analysis of MCT1 expression in BC tissue samples indicated the highest expression in TNBC than in $\mathrm{ER}+, \mathrm{PR}+$, or HER2+ BC.

Additionally, MCT1 expression correlates with the aggressiveness, recurrence, reduced survival, and tumorigenicity $[52,84]$ in BC. Hyperglycolytic activity due to lactate efflux can be inhibited using natural compounds, siRNA, and small molecule inhibitors (Table 1). Inhibition of MCT1 using inhibitors can have a direct influence on lactate transport and intracellular $\mathrm{pH}$ regulation and can control cancer cell viability [53]. Morais-Santos F. et al. [53] observed differences in sensitivity to MCT1 inhibitors among various subtypes of BC. Here, they observed and reported that basal subtypes showed a difference in sensitivity to MCT1 inhibitors such as quercetin, $\alpha$-cyano-4-hydroxycinnamate (CHC), and lonidamine (Figure 1A). In the case of quercetin, basal type BC (MDA-MB-468, Hs 578T) with high MCT1 expression showed more sensitivity to quercetin than BC with low MCT1. In these cell lines, the concomitant reduction in glucose consumption and lactate production was observed. 
Conversely, BT-20 basal type cells were insensitive to all three MCT1 inhibitors, despite high MCT1 expression [53]. This study emphasizes the different mechanisms by which the inhibitors target the receptor and how the difference in sensitivity varies with the metabolic phenotypes in various subtypes of BC. Further research in the area of metabolic phenotypes towards predicting drug sensitivity is warranted to advance in target-based therapy. However, the clinical use of MCT1 inhibitors has been reported to have serious side effects like myopathy [85].

Sodium/glucose co-transporter 1 (SGLT1) is essential for maintaining intracellular glucose concentration and can promote tumor growth by interacting with the epidermal growth factor receptor (EGFR) [86]. In vitro and in vivo analysis of SGTL1 transporter showed an important link between SGLT1-EGFR, regulating TNBC cell survival. mRNA analysis of this transporter in BC tissue samples indicated the highest expression in TNBC and HER2+ than in luminal A or luminal B [86]. The same research group also showed that knockdown of SGLT1 significantly reduced TNBC proliferation and tumor size.

\subsection{Targeting Enzymes of the Glycolytic Pathway}

Hexokinase (HK) catalyzes the first step in glucose metabolism converting glucose to glucose6-phosphate. There are four significant isoforms of HK, named HK1, HK2, HK3, and HK4, which differ in their cellular distribution and affinity to its substrate glucose. HK1 and HK2 are mitochondrial kinases and associated with AKT-mediated cell survival [87,88]. HK2 status is clinically linked to recurrence and poor prognosis in BC [37]. Clinical studies conducted on BC patients detected $44 \%$ positive out of 118 cases for high expression of HK2 [37]. Inhibition of HK2 has shown to inhibit proliferation and change the metabolic profile of cancer by shifting from glycolytic to OXPHOS pathway with reduced lactate formation [89]. 2-Deoxy-D-glucose (2-DG), a glucose analog, competes with glucose for GLUT transporters [90]. As 2-DG cannot be metabolized, it becomes cytotoxic to the cell [91], and HK can modulate 2-DG induced cytotoxicity [55]. A combination of polydatin (a precursor of resveratrol) with 2-DG induced apoptosis, inhibited metastasis, and invasion in MCF-7 cells via HIF- $1 \alpha / H K 2$ axis [92]. In vitro studies showed that metformin could directly inhibit HK2 activity in MDA-MB-231 cells and inhibit tumor growth in vivo (Figure 1A) [54]. Interestingly, metformin showed selective inhibition of HK1 and HK2 isoforms. Parallelly, metformin decreased the glycolytic rate and activated the $5^{\prime}$ adenosine monophosphate-activated protein kinase (AMPK) pathway. Similarly, in another study, co-treatment with 2-DG and metformin in MDA-MB-231 cells caused the detachment of cells and activation of AMPK signaling [93]. 3-Bromopyruvate (3BrPy) is a potent inhibitor of glyceraldehyde-3-phosphate dehydrogenase (GAPDH) and HK2 and can be selectively taken up into the cell via the highly expressed MCT1 lactate transporter in tumor cells (Figure 1A) [58]. The advantage of facilitated drug delivery is that healthy cells can be spared, and only tumor cells tend to accumulate the drug, thus minimizing the side effects.

6-Phosphofructo-2-kinase/fructose-2,6-bisphosphatase-3 (PFKFB3) is an enzyme that controls the level of fructose-2,6-bisphosphate and is crucial in BC cancer progression [94]. Blocking PFKFB3 by 3-(3-pyridinyl)-1-(4-pyridinyl)-2-propen-1-one (3PO) can negatively regulate glycolysis and modulate rat sarcoma viral proto-oncogene (Ras) and protein kinase B (AKT) in HER2+ BC cells [56]. Inhibitors of PFKFB3 can target specific cell types such as cancer cells, cancer stem cells, endothelial cells, and immune cells [57]. Perhaps due to the ubiquitous nature of GAPDH, considering potential side effects when targeting it, the scope for developing GAPDH as an anticancer target has diverse opinions among the scientists [95]. Besides, several studies identified the prominent role of Lactate dehydrogenase A (LDHA) in TNBCs $[39,96,97]$. Oxamate, a competitive inhibitor of LDHA is a pyruvate analog that inhibited glycolysis and decreased the viability in both paclitaxel sensitive and resistant MDA-MB-435 cells (Figure 1A) [62]. Galloflavin, another LDHA inhibitor, showed two different mechanisms of inhibition of cancer cell proliferation (Figure 1A). In MCF-7 cells, the inhibition of proliferation by galloflavin correlated to the downregulation of cell survival pathway. Galloflavin induced oxidative stress that, in turn, suppressed cell proliferation of TNBC (MDA-MB-231) cells [98]. 
Certain compounds, such as chidamide, inhibited glycolysis via a miRNA-33a-5p-mediated inhibition of LDHA in MDA-MB-231 and BT20 cells (Figure 1A) [64]. It is important to note that several flavonoids manifested anticancer potential via inhibition of the glycolytic enzymes. EGCG suppressed mRNA levels and activities of glycolysis-related enzymes, including HK2, PFK, LDH, and PKM2, in $4 \mathrm{~T} 1$ cells [49]. Additionally, quercetin-regulated glucose uptake and the production of lactic acid reduced the level of PKM2 and LDHA in MCF-7 and MDA-MB-231 cells [99]. An interesting phenomenon represents a binding between the mitochondria membrane and HK2. An interaction between voltage-dependent anion channels (VDACs) located in the outer mitochondria membrane and HK2 is tightly associated with resistance to apoptosis. Moreover, recent evidence revealed that HK2/VDAC interaction led to the development of drug resistance. An essential role of HK2 in resistance to gemcitabine (GEM)-induced apoptosis was demonstrated in pancreatic cancer. It has been observed that HK2 dimerization promoted interaction with VDACs, resulting in inhibition of GEM-induced apoptosis [100]. One possibility to circumvent HK2/VDACs interaction represents the application of synthetic or natural drugs able to disrupt mitochondrial binding of HK2. Recently, Guo Y. et al. [101] used synthesized flavonoid GL-V9 against BC MCF-7 and MDA-MB-231 cell lines. Obtained data showed that GL-V9 induced dissociation of HK2 from VDAC, leading to inhibition of glycolysis and mitochondrial-mediated apoptosis. Similarly, another synthesized flavonoid FV-429 disrupted the interaction between HK2 and VDAC in MDA-MB-231, resulting in cell death [102]. Targeting HK2/VDAC interaction thus represents a promising approach to overcome drug resistance and inducing apoptosis in cancer cells. In summary, beneficial properties of phytochemicals can act as powerful tools against tumor development via modulation of cancer cells metabolism, and their combination with classical anticancer drugs brings new opportunities in the therapeutic strategy of the 21st century.

\subsection{Targeting Components of Mitochondria}

While discussing the dependence of cancer cells on aerobic glycolysis, it is essential to highlight the metabolic flexibility of cancer under hypoxic and normoxic conditions. Tumors become increasingly hypoxic with an increase in distance from the blood vessel, and those cancer cells nearer to the blood vessel will be better oxygenated; therefore, the region will bear a normoxic signature [103]. Moreover, there is a mutual association between stromal cells and cancer cells for metabolic purposes in the tumor. Cancer cells induce stromal cells to rely on aerobic glycolysis, and the metabolites accumulated by stromal cells are used by cancer cells for mitochondrial OXPHOS pathway. Instead of targeting aerobic glycolysis alone, a more efficient anticancer strategy is to target mitochondrial metabolism as well [104].

Arsenic trioxide $\left(\mathrm{As}_{2} \mathrm{O}_{3}\right)$ is a classical anticancer drug used in the treatment of different forms of cancer. It can generate ROS and interfere with multiple signaling pathways [105]. A combination of $\mathrm{As}_{2} \mathrm{O}_{3}$ and dichloroacetate (DCA) inhibited $\mathrm{BC}$ cell proliferation, in which $\mathrm{As}_{2} \mathrm{O}_{3}$ disrupted mitochondrial function by targeting complex IV and DCA blocked PDK activity (Figure 1A, Table 1). Apart from targeting GLUT, HK, and LDHA, metformin can also inhibit complex I of the respiratory chain and also decrease citrate in TCA cycle [67].

\section{Altered Glucose Metabolism and Anticancer Drug Resistance}

Tumor metabolism does not only contribute to cancer progression but also to therapy resistance and can influence drug sensitivity. The increased demand for energy in resistant cells was consistent with the enhanced activity of drug efflux and drug detoxification mechanism of the cells [9]. The contribution of glycolytic enzymes in drug resistance is discussed in detail in Figure 1B.

\subsection{Hexokinase and Drug Resistance}

HK2 is highly expressed in cancers of the stomach, ovary, and cervix [106,107], and is associated with elevated glycolytic flux, which is a characteristic of cancer cells. Ahn K.J. et al. [88] investigated 
the role of increased expression and activity of HK2 in the proliferation of cancer cells. In hepatocellular cancer, they showed a twofold increase in cell survival and an eight-fold increase in resistance to cisplatin. Here, the non-glycolytic role of HK2 was mediated via PI3K/AKT/AMPK signaling. An in-depth study of HK2 function in ovarian cancer cell line revealed its extended role in migration, stemness, and invasion via FAK/ERK1/2/NANOG/SOX9 pathway [107]. A novel interaction between proviral insertion in murine lymphomas 2 (PIM2) and HK2 was discovered by Yang T. et al. [108]. PIM2 regulates aerobic glycolysis by phosphorylating HK2 (Figure 2A). Both PIM2 and HK2 are upregulated in BC tissue and contribute to paclitaxel resistance (Figure 1B) [108]. PIM2-mediated HK2 activity is a potential target for the treatment of BC [108]. Studies related to PIM2 showed that it regulates cell cycle progression, negatively regulates apoptosis, and correlates with malignant phenotypes. Thus, blocking PIM2 can induce apoptosis, cell cycle arrest, and senescence [108]. Studies report the role of HIF- $1 \alpha$ in HK2 expression, e.g., inhibition of HK2 resensitizes tamoxifen-resistant cells (Figure 1B) [35] and HIF-1 $\alpha$, a transcription factor associated with hypoxia, is linked to cancer initiation.

\subsection{PFKFB3 and Drug Resistance}

6-Phosphofructo-2-kinase/fructose-2,6-bisphosphatase 3 (PFKFB3), an essential regulator of glycolysis, has the highest kinase activity among its four known isoforms and mediates interconversion of fructose-6-phosphate to fructose-2,6 bisphosphate. PFKFB3 has a critical influence on various stages of cancer progression, such as proliferation, drug resistance, angiogenesis, etc. [57]. Abnormal expression of PFKFB3 was observed in cancers of the brain, colon, breast, and ovaries [109]. Immunohistochemical analysis of $74 \mathrm{BC}$ tissues revealed a positive correlation between PFKFB3 expression and metastasis and poor prognosis [94]. Additionally, it was demonstrated in MDA-MB-231 and MDA-MB-468 (TNBC) cells that the silencing of PFKFB3 inhibited proliferation, migration, and invasion and caused cell cycle arrest. Furthermore, PFKFB3 plays a vital role in angiogenesis and regulates the expression of p27, pAKT, and vascular endothelial growth factor alpha (VEGF $\alpha$ ). HER2+ BC cell lines (SKBR3 and BT-474) showed elevated levels of PFKFB3 transcripts, which clinically correlated with poor prognosis [94]. A hypothesis based on the role of HER2 signaling in PFKFB3 expression and its contribution to BC progression was reported by $\mathrm{O}^{\prime} \mathrm{Neal}$ J. et al. [56], who showed that enhanced HER2 expression elevated glycolysis by increasing the activity of PFKFB3. Treatment with PFKFB3 inhibitor 3PO showed a reduction in tumor size in HER2+ mouse model of BC [56]. Klarer A.C. et al. [110] reported an interesting finding as they described the induction of autophagy as a prosurvival mechanism with $3 \mathrm{PO}$ treatment and thus recommended the use of an autophagy inhibitor along with $3 \mathrm{PO}$ for improved antitumor efficacy. Furthermore, inhibition of HER2 by lapatinib showed a reduction in glucose uptake and PFKFB3 transcript [56]. This proves that HER2 modulates tumor glycolysis by regulating PFKFB3 expression. A combination of PFKFB3 inhibitor and trastuzumab targeting HER2+ BC should be effective in resistant BC as well. PFK158, another PFKFB3 inhibitor, was shown to synergize with carboplatin and paclitaxel in the treatment of chemoresistant gynecologic cancers [111].

\subsection{Enolase and Drug Resistance}

Enolase (EN), a key glycolytic enzyme contributing to the Warburg effect, is used as a prognostic marker in lung cancer [112]. Moreover, EN is also an important marker in BC, as was demonstrated by an analysis of 244 BC tissue samples that revealed highly detected EN-1 in ER+ BC. Patients with high EN-1 showed poor prognosis with more extensive tumor volume, poor nodal status, and longer distance relapse [113]. Nevertheless, the knockdown of EN expression using siRNA significantly enhanced cytotoxicity to $100 \mathrm{nM}$ tamoxifen in the treatment of tamoxifen-resistant BC cells. An upregulated EN-1 suppresses c-Myc expression, which results in the survival of resistant cells (Figure 1B) [36].

Additionally, proteomics profiling revealed that the silencing of EN-1 restored the oxidative phosphorylation by driving pyruvate to acetyl-CoA and TCA cycle in BC MDA-MB-231 cells. Apart from that, EN-1 silencing induced oxidative stress, senescence, and increased reactive oxygen species (ROS) production, followed by reduced glutathione in the same cell line [114]. Above all, targeting EN-1 is 
a novel strategy for treating tamoxifen-resistant BC (Figure 1A). EN-1 is also a right candidate as a prognostic marker for BC patients undergoing tamoxifen treatment [36].

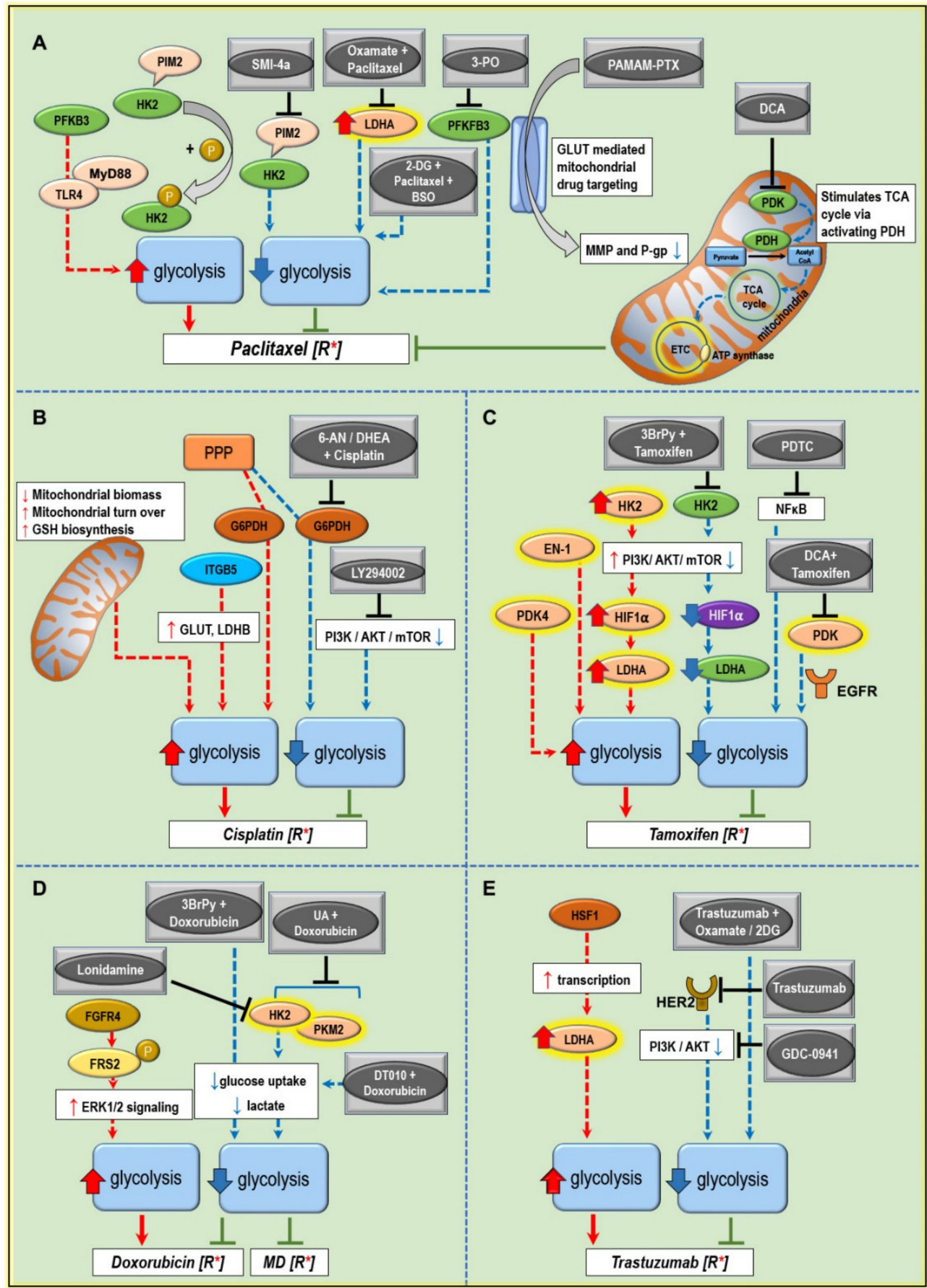

Figure 2. Illustrating the metabolic components contributing to drug resistance and drugs to overcome the resistance. The five panels show various signaling pathways converging to increased glycolysis and drugs as monotherapy or combinations that modify these pathways, which help to reverse the resistance mechanism. (A) Metabolic components contributing to paclitaxel resistance include upregulated expression of GLUT, HK2, LDHA, and PFKFB3, thereby switching the metabolism of cancer cells to aerobic glycolysis. Drugs targeting these enzymes potentially downregulate aerobic glycolysis, lactate production, and drug efflux pumps. PAMAM-PTX is a conjugated drug targeted to 
mitochondria via GLUT [115]. (B) Targeting PI3K/AKT pathway and G6PDH can reverse cisplatin resistance [116]. (C) Increased expression of EN, PDK4, HK2, and LDHA confers resistance to tamoxifen. PI3K/AKT pathway plays an essential role in Warburg's effect [117]. (D) Various combinations of drugs can reverse the glycolytic phenotype and reverse multidrug resistance. Lonidamine and 3-BrPy are already in the clinical trial phase. (E) A combination of drugs targeting HER2 can downregulate PI3K/AKT and decrease aerobic glycolysis by resensitization of cancer cells to trastuzumab. Drug interventions that inhibit the non-glycolytic and tumor-promoting functions of the enzymes/pathway components are shown as black T-ended stop bar. The red arrows indicate components and pathways that contribute to drug resistance, thereby promoting tumor progression. In contrast, the blue arrows indicate components and pathways that contribute to the reversal of drug resistance/resensitization to the drug, thus supporting tumor suppression/regression. The green T-ended stop bar indicates the reversal of resistance/resensitization to the drug.

\subsection{Pyruvate Kinase and Drug Resistance}

In the glycolytic pathway, pyruvate kinase (PK) catalyzes the conversion of phosphoenolpyruvate to pyruvate and generates ATP by transferring the phosphate moiety to ADP. In humans, PK exists in four isoforms: PKM1, PKM2, PKR, and PKL [118]. Apart from regulating glucose metabolism, research over the years has identified noncanonical functions of PK, which includes the modulation of gene expression, epigenetics, cell cycle regulation, and cell-cell communication [119]. An extensive review of PK by Israelsen W.J. and Van der Heiden M.G. [118] discusses multiple roles of PK and its function in the modulation of tumor microenvironment in cancer. Moreover, an interesting study by Hsu M.C. and Hung W.C. [119] mentions the prominent role of PKM2 in cancers and the metabolic switching from PKM1 to PKM2 isoform during carcinogenesis [120]. Additionally, a clinical study revealed a strong correlation between PKM2 and poor overall survival in cancers of the digestive system, but this was not confirmed in pancreatic cancer in which strong PKM2 expression correlated with improved overall survival [121]. Nevertheless, its role as a diagnostic marker in lung and colon cancer is contradicted by its poor specificity [122].

In BC, the association of PKM2 with VEGF-C was investigated in $218 \mathrm{BC}$ patients in whom the mRNA levels of both were upregulated in tumor tissue compared to regular counterparts [123]. Moreover, the knockdown of PKM2 inhibited glycolysis and protein levels of VEGF-C, which subsequently reduced cancer cell proliferation in BC MCF-7 and MDA-MB-231 cells [124]. Combined expression of the above proteins in the clinical samples was associated with worse histological grade, lymph node metastasis, lymphovascular invasion, and poor patient survival $[123,125]$. Besides, the analysis of PKM1 and PKM2 expression in TNBC showed high expression of both proteins and targeting PK inhibited the proliferation of TNBC MDA-MB-231 and MDA-MB-436 cells via inhibiting NFkB signaling pathway [124]. Clinical studies reported a correlation between PKM2 expression and the prediction of chemosensitivity to epirubicin and 5-flurouracil (5-FU) based on the immunohistochemical analysis done in 296 patients diagnosed with invasive BC [126]. Other studies confirmed the inhibition of proliferation of cancer cells by decreasing the activity of PKM2. For example, combining paclitaxel with shikonin, a natural product isolated from Lithospermum erythrorhizon improved the efficacy to sensitize aggressive BC cells to paclitaxel [61]. Furthermore, inhibition of PKM2 using miRNA-122 overexpression resensitized resistant colon cancer to 5-FU [127]. In advanced BC, PKM2 expression correlated with cisplatin resistance [128]. Moreover, PKM2 enhanced chemotherapy resistance in ER+ BC models using MCF-7 and T47D cells through the promotion of aerobic glycolysis [129]. Conversely, a decreased PKM2 level was linked to cisplatin resistance in gastric carcinoma [130]. 
Overall, the significance of PKM2 as a prognostic marker depends on the type of cancer and the used chemotherapeutic agent. As mentioned before, a combination of markers could predict a more accurate clinical outcome in BC treatment.

\subsection{LDHA and Drug Resistance}

LDH is a key glycolytic enzyme in the conversion of pyruvate to lactate. LDHA is aberrantly expressed in many cancers, including breast, kidney, lung, and ovarian cancers [96,131,132]. Cancers relying on aerobic glycolysis generate more lactate [11]. ATP generated from aerobic glycolysis is predominantly utilized for tumor growth and metastasis. However, the knockdown of LDHA attenuated aerobic glycolysis and lactate production in murine $4 \mathrm{~T} 1$ breast tumor cells [133]. The biochemical characterization of LDHA showed that phosphorylation at Y10 (tyrosine) confers metastatic potential in both in vitro and in vivo BC model. LDHA phosphorylation is regulated by HER2, whose expression is higher in BC tissue compared to healthy breast tissue [134]. LDHA phosphorylation at Y10 is a potential prognostic marker for metastatic BC. LDHA does not only mediate cancer progression, but it can also influence the sensitivity of BC cells to anticancer drugs. Studies investigating the role of LDHA in drug resistance reported a link between LDHA and paclitaxel resistance (Figure 1B) [62]. Oxamate, an inhibitor of LDHA, combined with paclitaxel-induced apoptosis in paclitaxel-resistant BC (MDA-MB-435 and MDA-MB-231) cells by inhibiting cellular glycolysis (Figure 2A). Therefore, LDHA is a potential therapeutic target for overcoming paclitaxel resistance and resensitizing $B C$ to paclitaxel [62]. Moreover, the inhibition of LDHA also reverted the tamoxifen-resistant phenotype by inducing apoptosis and inhibiting the prosurvival autophagy in tamoxifen-resistant BC (MCF-7 and T47D) cells [135]. Independent studies showed a relatively higher expression of LDHA and AMPK activation in TNBC cells [96]. Analysis of TNBC tissue samples demonstrated a stronger correlation of LDHA and AMPK with distant metastasis, Ki67, and overall survival $[96,136]$. Interestingly, the LDHB isoform was differently expressed within various subtypes of TNBC and predicted a basal-like subtype of TNBC. LDHB isoform was reported low in hormone receptor-positive/HER2-negative cancers [137].

\subsection{PDH/PDK and Drug Resistance}

Pyruvate dehydrogenase (PDH) is a part of the pyruvate dehydrogenase complex (PDC) in the glycolytic pathway converting pyruvate to acetyl-CoA [138]. PDH is regulated by the inhibitory action of pyruvate dehydrogenase kinase and is reactivated by pyruvate dehydrogenase phosphatase depending upon changes in the levels of pyruvate/acetyl CoA and NADH levels [139]. Under pathological conditions like cancer, this regulation is substantially altered [140]. An upregulated PDK is implicated in many cancers; its role in aerobic glycolysis, drug resistance, and metastasis has been well documented [141]. Furthermore, studies reported enhanced expression of PDK1 isoform promoting BC stem cell (BCSC) properties [142]. Another group reported the involvement of PDK4 isoform in regulating aerobic glycolysis and mitochondrial respiration in BC. Its high expression correlated with poor prognosis in $\mathrm{BC}$ treatment irrespective of $\mathrm{BC}$ molecular subtypes.

Further investigation revealed the transcriptional regulation of PDK4 by miRNA-211, while inhibition of PDK4 by miRNA-211 induced a shift from glycolytic phenotype to OXPHOS dominant phenotype in BC MDA-MB-468 and BT-474 cells [138]. Furthermore, Walter W. et al. [143] identified the altered regulation of PDH by PDK4 and the association of PDK4 and anti-estrogen resistance in BC cells [143]. However, in colorectal cancer tissue, PDK1 had no role, but its PDK3 isoform was associated with cancer progression. Moreover, hypoxia-mediated enhanced expression of PDK3 inhibited drug-induced apoptosis, thus conferring drug resistance in colorectal cancer cell lines (HCT116 and HT29) [144]. Recent research suggests that inhibition of PDK can control cancer growth by regulating aerobic glycolysis [145]. Aspirin could effectively reduce the stemness and aerobic glycolysis in BC cell lines by inhibiting PDK1 and stemness related factors octamer-binding transcription factor 4 (OCT4), sex-determining region Y-box 2 (SOX2), and homeobox transcription factor (NANOG) [142]. Combining PDK1 inhibitors (triciribine and tetrandrine) with tamoxifen was found to resensitize BC to tamoxifen 
treatment [146]. Therefore, PDK inhibitors are potent anticancer agents [147]. Furthermore, new studies highlight the critical role of mitochondrial pyruvate carrier (MCP) in tumor energy metabolism. In a recent study, inhibition of MCP by 7ACC2 resulted in decreased lactate uptake by cancer cells for its energy requirements. In vivo studies showed that MCP inhibition reduced tumor volume and increased radiosensitization of tumors [148].

\section{Modulating Glucose Metabolism to Increase the Anticancer Drug Efficiency and Combat Treatment Resistance}

A growing body of literature asserts the role of tumor metabolism in the transformation process in cancer. Drugs modifying glucose metabolism positively favor the action of conventional chemotherapeutic drugs commonly used for cancer treatment. The following section discusses the metabolic alterations in the glucose metabolism in cancers associated with resistance towards conventional drugs used in BC and the possible ways to resensitize aggressive BC phenotypes (Figure 2).

\subsection{Paclitaxel Resistance}

Paclitaxel is a chemotherapeutic drug frequently used in TNBC treatment [149]. Though the initial response to paclitaxel is impressive, the majority of $\mathrm{BC}$ patients often develop resistance, ultimately leading to relapse, metastasis, and death [150].

A comparative in vitro study in a paclitaxel-resistant and -sensitive BC (MCF-7) cell line showed higher resistance to paclitaxel, cross-resistance to doxorubicin, and prolonged doubling time. Resistant cell lines also showed low ER status and upregulated HER2 and Ki-67 expression. Other resistant factors found in the multidrug-resistant (MDR) phenotype, such as P-glycoprotein (P-gp), lung resistancerelated protein (LRP), and glutathione-S-transferase- $\pi$ (GST- $\pi$ ), were also upregulated in the resistant cell line [151]. The underlying mechanisms contributing to the paclitaxel resistance are multiple. The most common mechanism seen in paclitaxel resistance is drug efflux by ABC transporters [152] and the involvement of drug detoxification enzymes cytochrome P450, CYP3A4/5, and CYP2C8 [153]. The energy required for drug efflux is derived mainly from the glycolytic pathway [154]. An interesting study conducted by Zuo K.Q. et al. [155] compared paclitaxel binding proteins between resistant MCF/Paclitaxel cell line and the sensitive phenotype, and they identified proteins such as heat shock protein 90, actinin and dermcidin precursor being absent in the resistant phenotype. The dermcidin precursor is associated with metabolism and has a prominent role in tumor cell survival [156]. As previously reported, paclitaxel induces oxidative stress in BC MDA-MB-231 and T-47D cells [157].

Nevertheless, when combined with 2-DG (glycolytic inhibitor) and buthionine sulfoximine (BSO) a glutathione synthesis inhibitor, the sensitivity towards paclitaxel was enhanced due to hydrogen peroxide $\left(\mathrm{H}_{2} \mathrm{O}_{2}\right)$ and superoxide $\left(\mathrm{O}_{2}{ }^{\bullet-}\right)$ production (Figure 2A). 2-DG was tested at pre-clinical or phase I/II clinical trial for BC treatment [158]. As mentioned in Section 4.5, LDHA, which is predominantly expressed in $\mathrm{BC}$ tissue, has a significant role in nutrient exchange within the tumor microenvironment [62,159]. In vitro studies in the paclitaxel-resistant BC MDA-MB-435 cell line showed a 2-fold increase in $\mathrm{LDH}$ activity. The half maximal inhibitory concentration $\left(\mathrm{IC}_{50}\right)$ values from cell viability assay were 30-fold higher compared to the parental cell line. LDHA expression and its activity play a direct role in the paclitaxel resistance. Downregulation of LDHA using siRNA increased the sensitivity to paclitaxel by 2 -fold, showing that targeting glycolytic enzyme can resensitize the resistant cell to paclitaxel. Consistent with the above observations, siRNA mediated knockdown of LDHA and combining paclitaxel with oxamate, an analog of pyruvate, significantly inhibited the viability and induced apoptosis in paclitaxel-resistant BC cells (Figure 2A) [62]. Likewise, in vivo studies underlined that paclitaxel and oxamate combination induced synergistic cytotoxic effects, apoptosis, and antiangiogenic activity in a murine BC model [160]. 
Moreover, $\mathrm{PFKFB} 3$, a critical glycolytic regulator, was examined for its role in paclitaxel resistance in hormone receptor-positive BC (MCF-7RA and MCF-7RB) cell lines. The silencing of PFKFB3 markedly reduced the $\mathrm{IC}_{50}$ concentrations in resistant phenotypes of both $\mathrm{BC}$ cell lines. Furthermore, upon paclitaxel exposure, PFKFB3 regulated the expression of TLR4, MyD88, and interleukin release in the tested cell lines (Figure 2A) [161].

Dysregulated cell cycle machinery and the subsequent uncontrolled proliferation of cells are commonly featured in all cancers. Cell cycle components cyclin D and E, CDK4/6, and CDK2 show altered expression in TNBC [162]. Cell cycle inhibitors are commonly used in the treatment of ER+, HER2 - BC patients [163]. However, the cell cycle inhibitor against CDK4/6 has proven efficiency in a subtype of TNBC whose genotype is Rb-positive, p16 ${ }^{\text {INK4 }}$-negative [162]. Recently, a study tested the efficacy of CDK4/6 inhibitor, palbociclib, along with paclitaxel in TNBC MDA-MB-231 and HCC38 cell lines following a different time and exposure regime (simultaneous or sequential). The simultaneous application of CDK4/6 inhibitor along with paclitaxel encountered an antagonistic effect in both cell lines.

Conversely, the sequential application of palbociclib followed by exposure to paclitaxel inhibited proliferation and induced apoptosis of tested cells. Mechanistically, pretreatment of cells with palbociclib and the subsequent removal of palbociclib before paclitaxel application helped to synchronize the cell cycle re-entry from the G1 phase to S phase, which rendered cells susceptible to the cytotoxic drug. Above all, palbociclib is capable of reprograming the glucose metabolism by downregulating GLUT-1 glucose uptake via Rb/E2F/c-Myc signaling pathway. It also inhibits HIF-1 $\alpha$ expression, a key regulator of tumor progression [162].

Another feature observed in the paclitaxel-resistant cells is the decreased level of citrate and defective mitochondrial respiration. As observed in human lung adenocarcinoma A549 cells, dichloroacetate (DCA) can normalize mitochondrial function by inhibiting pyruvate dehydrogenase kinase (PDK) and reverse paclitaxel resistance. Inhibition of PDK activates pyruvate dehydrogenase complex (PDC), thereby activating the conversion of pyruvate to acetyl CoA and entry of the later into TCA cycle to form citrate. This process activates the oxidative phosphorylation in mitochondria. Additionally, DCA inhibits the activity of P-gp protein associated with drug efflux by inhibiting glycolysis [164] (Table 2).

Moreover, the aberrant Wnt signaling pathway is highlighted in many cancers, including $\mathrm{BC}$, and is associated with poor prognosis [165]. A review of Wnt signaling highlights its role in tumor metabolism [166]. A dysregulated canonical Wnt/ $\beta$-catenin pathway through c-Myc enhances proliferation, aerobic glycolysis, alanine-serine-cysteine transporter 2 (ASCT2) levels, and glutathione levels contributing to therapy resistance [166]. A comparative study between resistant and parent (MCF-7) cells showed increased expression of HER2 and $\beta$-catenin in the resistant phenotype. The neuroleptic agent penfluridol suppressed chemoresistance of paclitaxel-resistant $B C$ cells by modulating HER2/ $\beta$-catenin signaling via downregulating HER2, $\beta$-catenin, c-Myc, and cyclin D1 [167]. Targeted therapies towards Wnt signaling are currently evaluated in the pre-clinical/clinical trial stage [165]. Furthermore, ursolic acid (UA), a plant-derived triterpene, reversed the chemoresistance to paclitaxel in BC MDA-MB-231 cells by targeting MyD88 via miRNA-149-5p. The miRNA-149 plays a significant role in suppressing different oncogenes and is frequently downregulated in $\mathrm{BC}$. Overexpression studies with miRNA-149 demonstrated an inhibition of PI3K/AKT signaling pathway and MyD88 and a reverse of resistant to sensitive phenotype [168]. Additionally, an alkylating agent temozolomide exerted its anticancer effect by downregulating glucose metabolism. A combination of temozolomide and paclitaxel can synergistically inhibit paclitaxel-resistant brain tumors (gliomas) [169]. 
Table 2. Combination therapy with glycolytic inhibitors in BC chemotherapy.

\begin{tabular}{|c|c|c|c|c|c|c|c|}
\hline Drug & Model & Dose & Observation & Side Effects & Mechanism & Study Method & Ref. \\
\hline $\begin{array}{c}\text { DCA + } \\
\text { cisplatin }\end{array}$ & $\begin{array}{l}\text { Stage IV BC } \\
\quad(1 \text { case })\end{array}$ & DCA $6.25 \mathrm{mg} / \mathrm{kg}$ & - & $\begin{array}{l}\text { Pulmonary } \\
\text { embolism, } \\
\text { edema }\end{array}$ & - & $\begin{array}{l}\text { NCT01029925 } \\
(2014)\end{array}$ & [170] \\
\hline $\begin{array}{l}\text { Oxamate }+ \\
\text { paclitaxel }\end{array}$ & $\begin{array}{l}\text { Solid Ehrlich } \\
\text { Carcinoma }\end{array}$ & $\begin{array}{c}\text { Oxamate } \\
(300 \mathrm{mg} / \mathrm{kg}) \text { and } \\
\text { paclitaxel } \\
(10 \text { or } 20 \mathrm{mg} / \mathrm{kg})\end{array}$ & $\begin{array}{c}>40 \% \text { Reduction } \\
\text { in volume of SEC, } \\
\text { ATP, IL- } 17\end{array}$ & - & $\begin{array}{l}\text { LDH-A inhibition } \\
\text { induced apoptosis }\end{array}$ & In vivo & [160] \\
\hline $\begin{array}{l}\text { Doxorubicin }+ \\
\text { metformin }+ \\
\text { oxamate }\end{array}$ & TNBC xenograft & $\begin{array}{c}\text { Doxorubicin } \\
1 \mathrm{mg} / \mathrm{kg}, \mathrm{Metformin} \\
200 \mathrm{mg} / \mathrm{kg}, \\
\text { and Oxamate } 15 \mathrm{mg} / \mathrm{kg}\end{array}$ & $\begin{array}{l}\text { Reduced } \\
\text { tumor volume }\end{array}$ & - & $\begin{array}{l}\text { LDH-A inhibition } \\
\text { induced apoptosis }\end{array}$ & In vivo & [171] \\
\hline $\begin{array}{l}\text { Doxorubicin }+ \\
\text { lonidamine }\end{array}$ & $\begin{array}{l}\text { Metastatic BC } \\
\text { patients }\end{array}$ & $\begin{array}{c}\text { Doxorubicin } \\
75 \mathrm{mg} / \mathrm{m}^{2} / 21 \text { day }+ \\
\text { lonidamine } \\
600 \mathrm{mg} / \mathrm{m}^{2} / \text { day }\end{array}$ & $\begin{array}{l}\text { Overall response } \\
\text { rate is } 68 \% \text { in } \mathrm{BC} \\
\text { with liver } \\
\text { metastasis }\end{array}$ & $\begin{array}{l}\text { Cardiotoxicity, } \\
\text { myalgia }\end{array}$ & - & $\begin{array}{l}\text { Randomized } \\
\text { clinical trial } \\
\quad(1998)\end{array}$ & [172] \\
\hline $\begin{array}{l}\text { Trastuzumab + } \\
\text { metformin } \\
\text { Paclitaxel }+ \\
\text { trastuzumab + } \\
\text { metformin }\end{array}$ & $\begin{array}{c}\text { Xenograft } \\
\text { HER2+ primary BC }\end{array}$ & $\begin{array}{c}\text { Trastuzumab } \\
5 \mathrm{mg} / \mathrm{kg} / \text { once a week }+ \\
\text { Metformin } \\
12 \text { cycles of weekly } \\
\text { paclitaxel } 80 \mathrm{mg} / \mathrm{m}^{2}+ \\
\text { Metformin } \\
1500 \mathrm{mg} / \text { day }\end{array}$ & $\begin{array}{l}\text { Reduced the } \\
\text { tumor volume by } \\
\text { 4-fold in HER2+, } \\
\text { trastuzumab } \\
\text { resistant tumor }\end{array}$ & $\begin{array}{l}\text { Metformin } \\
\text { reduces the } \\
\text { cardiotoxicity } \\
\text { induced by } \\
\text { trastuzumab }\end{array}$ & $\begin{array}{l}\text { Metformin lowers } \\
\text { circulating } \\
\text { insulin-like } \\
\text { growth factor } \\
\text { (IGF). Inhibition } \\
\text { of AMPK/mTOR/ } \\
\text { p70S6K1 pathway }\end{array}$ & $\begin{array}{l}\text { In vivo } \\
\text { Phase II trial } \\
\quad(2010)\end{array}$ & {$[174,175]$} \\
\hline
\end{tabular}

\subsection{Cisplatin Resistance}

Cisplatin (cis-diamminedichloroplatinum (II)) is a cytotoxic drug commonly used in the treatment of cancers of the breast, cervix, head, neck, and prostate $[176,177]$. Its mechanism of cytotoxicity is mainly associated with the formation of DNA adducts, eventually inducing apoptosis in cancer cells. Though cisplatin is a potent cytotoxic agent, the emergence of resistance is often seen during long-term treatment in which the tumor fails to respond to clinically relevant dosages. Resistant tumors respond only to almost double the standard concentration. Factors contributing to cisplatin resistance are many and include reduced drug intake, enhanced drug efflux, and drug detoxification. Resistance to cisplatin is also associated with cell signaling components such as PI3K/AKT and HER2 expression. Additionally, an attenuation of Ras and MAPK pathway also mediates cisplatin resistance [178].

The glycolytic components conferring resistance to cisplatin include altered glycolytic enzymes and glucose transporters [179]. Better observation of the metabolic role in cisplatin resistance was described in the ovarian cancer cell line [116]. Compared to cisplatin-sensitive ovarian cancer cells, the resistant cells showed no change in glucose uptake at an early point of drug application. Interestingly, protein levels of GLUT-1 showed no change, but a change was observed in the localization of GLUT-1 after cisplatin treatment of tested cells. It is possible that cisplatin can bind to tubulin and can inhibit the transportation of GLUT-1 to the plasma membrane [180]. Another study reported a downregulation of GLUT-1, GLUT-4, and LDHB via integrin $\beta 5 /$ focal adhesion kinase (ITGB5/FAK) signaling in MDA-MB-231 (TNBC) and cervical cancer cell line Siha (Figure 2B) [63]. Besides, a fusion of cisplatin and dichloroacetate-platinum (II)-DCA reported an efficient cytotoxic effect in ovarian cancer cell line by a mechanism based on the dual targeting of DNA and mitochondria [181].

Similarly, based on the principle of dual targeting, a novel mitochondrial inhibitor, 4-(N-(S-penicillaminylacetyl) amino) phenylarsonous acid (PENAO), along with DCA demonstrated cytotoxicity in BC T47D and MDA-MB-231 cells [182]. Despite that DCA was also tested in a clinical trial, an evaluation of its response rate in patients with metastatic $B C$ was not associated with clear results [170]. Moreover, a combination of metformin and cisplatin had a synergistic effect on cisplatin-resistant TNBC (Hs 578T and MDA-MB-231) cells by a mechanism not directly related to the glycolytic pathway. Here, metformin downregulated the expression of RAD51, a protein often linked 
to resistance to DNA damaging cytotoxic agents. However, the antineoplastic efficiency of metformin was reduced by high external glucose concentration [183].

\subsection{Tamoxifen Resistance}

Tamoxifen is administered in patients with ER+ BC [184]. BC, which initially responds to tamoxifen, often develops resistance to treatment [185]. Tamoxifen is a selective ER modulator [186]. ER plays a vital role in breast tumorigenesis by activating the survival pathway and can influence glycolysis by the regulation of GLUT-1 expression. Tamoxifen can inhibit mitochondrial respiratory complex I, thereby decreases ATP level and subsequently activates the AMPK signaling, leading to the induction of apoptosis through mTOR inhibition. Irrespective of ER status, tamoxifen affects tumor metabolism [117,187]. This indicates a mechanism independent of classical modulation of ER. A review by Manna S. and Holz M.K. [188] mentions that 5-10\% of ER-ve BC responds to Tamoxifen treatment. The mechanism involves ER-independent signaling components such as AKT phosphorylation, estrogen-related receptor alpha $(\mathrm{ERR} \alpha)$, TGF $\beta$ signaling, and characteristics of the tumor microenvironment. Tamoxifen demonstrated metabolic restabilization in BC (MCF-7 and MDA-MB-231) cells when combined with glycolytic inhibitor 2-DG or 3 bromopyruvate (3-BrPy) and in vivo data also showed similar results (Table 2) [189]. Another study demonstrated a two-fold increase in GLUT-1 expression in MCF-7 cells when stimulated with estrogen, while the presence of tamoxifen decreased this effect [44]. Besides, enhanced expression of HK2 and mTOR was reported in the tamoxifen-resistant MCF-7 cell line. Mechanism of tamoxifen resistance showed enhanced autophagy by HK2 via inhibition of the mTOR-S6K signaling [35]. A lower mTOR activity conferred the resistance to the drug. In tumors, both aerobic glycolysis and HIF-1 $\alpha$ stabilization can occur even in the absence of hypoxia driven by oncogenic signals. Woo Y.M. et al. [117] reported that AKT/mTOR pathway or AMPK signaling could activate HIF-1 $\alpha$ even in the absence of hypoxia [117]. Inhibition of HK2 suppressed AKT/mTOR/HIF-1 $\alpha$ axis and resensitized tamoxifen-resistant BC cell lines derived from MCF-7. Treatment with 3-BrPy, an inhibitor of $\mathrm{HK} 2$, reduced the cell viability as indicated by decreased glycolytic rate and lactate accumulation as well as cell cycle arrest at G1 phase (Figure 2C) [117]. Another key glycolytic enzyme, EN-1, also plays a role in tamoxifen resistance [36]. Enhanced EN-1 expression promotes cell survival by negative regulation of c-Myc promoter-binding protein (MBP-1)/c-Myc gene. Pretreatment of the tamoxifen-resistant MCF-7 cells with pyrrolidine dithiocarbamate (PDTC), an inhibitor of NFKB, resensitized them to tamoxifen by inhibiting transcriptional regulation of $\mathrm{EN}-1$ by $\mathrm{NF} \kappa \mathrm{B}$, thereby lifting inhibition of c-Myc by NFKB [36] (Figure 2C). A combination of tamoxifen and DCA inhibited the growth of tamoxifen-resistant MCF-7 cells by downregulating EGFR signaling [187]. All studies identify a common mechanism, specifically the involvement of AKT/mTOR/AMPK signaling in tamoxifen resistance in $\mathrm{BC}[117,190,191]$.

\subsection{Doxorubicin Resistance}

Doxorubicin (Adriamycin) is a drug widely used both in the early and late stages of BC [192]. Toxic side effects and the emergence of resistance is a common feature associated with doxorubicin treatment [192]. Multiple factors can contribute to doxorubicin resistance. Microarray analysis of MDA-MB-231 cells identified some critical proteins associated with doxorubicin resistance, which included cyclin D2, cytokeratin 18, and heterogeneous nuclear ribonucleoprotein m3-m4 [193]. P-gp, a significant factor contributing to drug efflux, is an essential player in drug resistance [194]. P-gp belongs to ATP-binding cassette family and requires energy in the form of ATP for functioning [195]. Some studies link glycolysis with drug efflux transporters [196]. Effects of 3-BrPy, a glycolytic inhibitor, was tested in doxorubicin-resistant neuroblastoma (NB) cells. 3-BrPy with doxorubicin synergistically inhibited cell viability of NB cells under both normoxic and hypoxic conditions. Consistent with the cell viability, total ATP levels, and lactate levels were reduced upon combination treatment with 3-BrPy with doxorubicin [196]. Here, the author assumes that 3-BrPy reduces the intracellular ATP levels, 
thereby affecting drug efflux transporter function, which is ATP-dependent and helps in anticancer drug retention within the cancer cell.

Moreover, the sensitivity to doxorubicin was compared in 2D and 3D cell culture models (MCF-7 and MDA-MB-231) of BC. This study identified a distinct factor, cell-to-ECM interactions, contributing to doxorubicin resistance in $\mathrm{BC}$. Integrins play an essential role in cell-to-ECM interactions; therefore, inhibition of $\beta 1$-integrin using antibody before doxorubicin treatment enhanced its cytotoxic effect [192]. Integrins have multiple functions, which include adhesion, migration, and proliferation, that are controlled by signaling pathways such as AMPK, mTOR, and HIF-1 (the role has been mentioned under tamoxifen resistance), and in turn, they also control other glucose metabolic pathway via $\beta 1$-integrin/FAK/PI3K/AKT/mTOR signaling [197]. A combination of DT-010, a conjugate of danshensu (DSS) and tetramethylpyrazine (TMP), and doxorubicin synergistically inhibited the viability of MCF-7 cells by downregulating glycolysis and inhibiting GRP78, a regulator of ER stress and aerobic glycolysis [198]. Another combination of doxorubicin with ursolic acid (UA) in doxorubicin-resistant MCF-7 cells, resulted in improved intracellular accumulation of doxorubicin probably by the inhibition of P-gp mediated by UA (Figure 2D) [199].

Moreover, metabolic alteration in doxorubicin-resistant BC cells revealed enhanced Fibroblast Growth Factor (FGF)-Fibroblast Growth Factor Receptor (FGFR) signaling and the activation of downstream signaling controlling various oncogenic processes such as angiogenesis, therapy resistance, and metastasis. Gene expression microarray revealed the role of FGFR in increased glycolytic flux and chemoresistance to doxorubicin. Blocking of FGF-FGFR-ERK1/2 signaling by pharmacological inhibitors targeting FGFR4 and ERK1/2 (PD173074 or U0126) resensitized resistant phenotype to doxorubicin treatment [200] (Figure 2D). Metformin, an antidiabetic drug, has demonstrated its antiproliferative effects in various BC cell lines and was able to sensitize the MDR phenotype [201]. A combination of metformin $(6 \mu \mathrm{M})$ and doxorubicin in the resistant phenotype of MCF-7 and MDA-MB-231 cells presented more cytotoxicity than doxorubicin alone, while metformin acted via IFN- $\alpha$ signaling pathway and by induction of cellular oxidative stress [202].

\subsection{Trastuzumab Resistance}

A recent review by Hoxhaj G. and Manning B.D. [203] highlights the significant role of PI3K/AKT pathway in the oncogenic process, including tumor energy metabolism. PI3K/AKT signaling has multiple control points in the glucose metabolic pathway, including glucose transporters and enzymes regulating glycolysis.

Trastuzumab (Herceptin), an antibody directed against HER2, is the first targeted therapy approved for HER2+ BC patients [204]. Mechanistically, trastuzumab inhibits the HER2 (ErbB2) receptor, and downstream signaling reduces the PI3K/AKT signaling by restoring PTEN function. Thus, trastuzumab, along with PI3K/AKT inhibitors, potentially increases the efficacy of cancer treatment [205]. A study of the molecular mechanism of trastuzumab action demonstrated inhibition of aerobic glycolysis via ErbB2-heat shock factor 1 (HSF1)-LDHA pathway (Figure 2E) while the sensitivity to trastuzumab was associated with LDHA activity [124]. HSF1 transcriptionally regulates LDHA, and a knockdown of HSF1 was associated with repressed LDHA expression in BC BT474 and SKBR3 cells (Figure 2E). Overexpression of HSF1 decreased the sensitivity of tested cancer cells to trastuzumab, thus confirming the role of HSF1 in the resistance (Figure 2E). Acquired resistance to trastuzumab is frequently encountered in metastatic BC [204]. Another key glycolytic enzyme valuable for assessing trastuzumab response in advanced metastatic BC is PKM2, while its level in the plasma is used as a marker for monitoring therapeutic progress [206]. As cancer is associated with altered metabolic phenotype, combining anticancer agents with glycolytic inhibitors is a promising strategy for improving treatment efficiency [207]. Combinations of trastuzumab with either 2-DG or oxamate synergistically inhibited cancer growth both in vitro and in vivo in comparison with these compounds alone [204]. 


\subsection{Palbociclib Resistance}

Palbociclib is one of the targeted therapies prescribed for (ER+/HER2-) BC patients undergoing endocrine therapy [208]. The development of resistance is observed in 50\% of patients in later stages of treatment [136]. A study highlighted a difference in glucose metabolism among ER+/HER2-/+ subtypes of BC cell lines exposed to palbociclib. Enhanced aerobic glycolysis was observed in ER+/HER2palbociclib sensitive cells, whereas increased glucose catabolism was observed in ER+/HER2+ palbociclib resistant cells [209]. Moreover, synergistic effects with palbociclib and endocrine therapy were reported in preclinical models [208].

\section{The Scope of Targeting Warburg's Effect for Resensitizing BC Chemotherapy}

The adaptability of neoplasms to switch between conditions of normoxic and hypoxic microenvironment confers a high degree of metabolic heterogeneity in various cancers, which in turn supports proliferation, growth, and progression while evading apoptosis [210]. Depending on their energy requirements, cancer cells can switch between various signaling pathways for resourcing metabolites from other pathways (such as glutamine, PPP, and fatty acid metabolism). Under this situation, the metabolic landscape of the tumor varies from the core towards the periphery of the tumor [211]. Therefore, the metabolic map derived from a tumor tissue may not represent the tumor as a whole [210]. Therefore, targeting a transient metabolic phenotype may be confusing from a therapeutic point of view unless otherwise, the target represents a permanent metabolic perturbation.

Therapy resistance is frequently encountered in the course of BC treatment in both endocrine-based therapy (for hormone receptor-positive BC) and chemotherapy (for TNBCs). Evidence shows that tumor metabolism is linked to the development of drug resistance. Targeting enzymes regulating energy metabolism is an efficient strategy complementing conventional treatment of BC. These targets are useful diagnostic and prognostic markers. Biomarkers representing the metabolic phenotypes are more useful prognostic markers, as in the case of HK2 and LDHA, which represents overall patient survival, metastasis, and progression $[37,96]$.

Interestingly, EN-1 is specifically related to resistance in ER+ BC. Therefore, targeting EN-1 could be beneficial in tamoxifen-resistant BC. Glycolytic inhibitors, like lonidamine, 3-BrPy, and 2-DG, in combination with anticancer agents, have encouraging results in pre-clinical studies. Reports also suggest the existence of a small group of breast cancer stem cells (BCSCs) that support tumor sustenance and have a critical role in the resistance to chemotherapy and radiotherapy. The proteomic and targeted metabolomic analysis showed metabolic alterations and adaptive mechanisms in BCSCs, such as a very high level of HIF-1 $\alpha$ that is predominantly relying on aerobic glycolysis [212].

Moreover, tumor-associated macrophages promote aerobic glycolysis and resistance to apoptosis of BC cells through extracellular vesicle transmission of HIF-1 $\alpha$ stabilizing long noncoding RNA (HISLA), while its blockage inhibits glycolysis and chemoresistance of BC in vivo [213]. Literature reports that glycolytic enzymes, including HK, PKM2, LDHA, and PDK, are related to BC stemness [212]. Therefore, inhibitors of these dysregulated enzymes are possible solutions to resistance in BC. 2-DG alone or along with doxorubicin combination overcomes drug resistance by eliminating BCSC [212].

\subsection{PI3K/AKT Pathway Is a Crucial Signal Contributing to Therapy Resistance}

In the 1920s, Warburg first reported a noticeable difference in the bioenergetics of cancer compared to healthy cells showing increased glucose metabolism and lactate production in tumor cells [10]. Many authors later confirmed this hypothesis by demonstrating the overexpression and dysregulated activity of key glycolytic enzymes (HK, PFKFB3, PK, and LDHA) and transporters (GLUT and MCT), followed by altered non-canonical function (here non-metabolic functions) of these enzymes [214]. HIF- $1 \alpha$, as a significant contributor to the Warburg effect, is associated with the regulation of many metabolic gene expressions [215]. Aberrant expression of these enzymes can facilitate oncogenic signaling, such as continuous proliferation signaling, migration, and inhibition of apoptosis [215]. 
Many signaling pathways are abnormally activated in drug resistance. The most crucial signaling regulating tumor metabolism is PI3K/AKT/mTOR [216]. This pathway, in turn, enhances the activity of HK, PK, and LDH enzymes of the glycolytic pathway and increases the glucose uptake in cancer cells and promotes the emergence of resistance [13]. Based on the literature reviewed in this current article, in the context of tumor metabolism, acquired resistance to chemotherapy is predominantly regulated by PI3K/AKT signaling [14,216,217]. PI3K/AKT confers resistance via multiple pathways such as inhibiting apoptosis through the downregulation of p53, activation of NFKB and subsequent transcriptional activation of drug efflux pumps, and survival signaling [218]. Therefore, multiple pieces of evidence support the fact that inhibition of PI3K and AKT could be useful in reversing the chemo-resistance of cancer cells.

\subsection{Targeting Glycolytic Enzymes Prove to Be Beneficial In Both In Vitro and In Vivo Cancer Models}

Downregulation of vital glycolytic enzymes can resensitize cancer to treatment by blocking aberrant metabolic pathways. Timing and sequence of administration of drugs can have two different outcomes, i.e., antagonistic or synergistic effect, as in the case of palbociclib/paclitaxel combination in which the simultaneous application of two drugs resulted in antagonistic effect whereas pretreatment for $24 \mathrm{~h}$ of palbociclib followed by paclitaxel showed an additive effect. These findings from the in vitro studies can be used in clinical settings when scheduling a treatment regime [162]. Paclitaxel resistance in lung adenocarcinoma cells is characterized by a defective mitochondrial respiratory function and decreased citric acid levels. Regulating glucose metabolism by activating TCA cycle can be an alternative strategy to reduce resistance, as in the case of paclitaxel treatment (Figure 2A) [164]. Moreover, insulin treatment caused a twofold increase in the cytotoxic effect of 5-FU and cyclophosphamide in BC MCF-7 cells [219]. Clinical studies also demonstrated the chemosensitization effect of insulin in BC patients undergoing chemotherapy. In a clinical trial involving multidrug resistant metastatic BC (resistant to fluorouracil + Adriamycin/doxorubicin + cyclophosphamide), a combination of insulin administration enhanced the antitumoral response to methotrexate. It significantly lowered the median increase in tumor size when compared to those who were administered with either insulin or methotrexate alone [220]. However, the mechanism of insulin-mediated potentiation of chemosensitivity is not clear yet. Understanding the underlying mechanism of drug resistance is essential to design improved drug molecules.

\subsection{Novel Methods to Improve Anticancer Drug Efficacy by Modulating the Tumor Glucose Metabolism}

Disruption of glucose metabolism for selective targeting of cancer is a novel approach, but the feasibility of targeting specific enzymes of the cancer tissue without affecting the healthy cells is not easy. A possible solution could be the novel PROteolysis Targeting Chimera (PROTACs) technology [221]. This technology uses ubiquitin-proteasome machinery to degrade undesirable cancer-promoting proteins. PROTACs is a bifunctional molecule with a ligand for recruiting the ubiquitin-proteasome and a second ligand to link to the target protein explicitly [179]. This method was successfully demonstrated in MCF-7 cells treated with HIF-1-estrogen Protac, in which the results showed functional downregulation of ER and subsequent growth inhibition [222]. However, this technology needs to be further advanced before being introduced to clinical trials. Based on the principle of Warburg's effect, another novel method for specific targeting of a tumor is glyco-conjugation of drugs, which ensures selective delivery of the cytotoxic drug to cancer cells (e.g., glufosfamide and 2-DG-conjugated paclitaxel) $[223,224]$. This technique utilizes highly expressed GLUT transporters expressed in cancers for improved uptake into the cells, thus minimizing side effects. More advanced drug designs, such as multicomponent conjugate drugs, demonstrate high efficacy and selectivity in targeting cancer cells. For example, unlike poorly soluble paclitaxel, PAMAM-paclitaxel-trastuzumab is a potent target-based drug, with increased permeability for HER2+ (SKBR-3) BC cells [115]. 


\subsection{The Power of Combinations for Enhanced Efficacy of Chemotherapy in $B C$}

The principle behind combination therapy is to combine drugs of different mechanisms to improve the overall anticancer efficacy and reduce drug resistance. Combinatory therapy produces a synergistic or additive effect compared to monotherapies. The use of anti-glycolytic inhibitors is beneficial in cancers in hypoxic conditions or with mitochondrial defects. Metformin, an antidiabetic drug, clinically showed improved chemotherapeutic and radiotherapeutic activity in combination with anticancer agents [45]. The combination of a more potent version of metformin, called phenformin (50 times), and oxamate was reported to be effective in various cancer cells, including BC [225]. Clinical data supports the finding that combining the classical anticancer drug with metabolic inhibitors resensitizes cancer to conventional chemotherapy and radiotherapy [226]. The selection of combination drugs should be guided by the analysis of tumor metabolic biomarkers in patient samples. In the case of heterogeneous tumors like TNBC, understanding the molecular or metabolic landscape can help in the selection and prediction of drug response, especially for those markers that are noninvasive and quantifiable and may be beneficial for continuous evaluation of treatment $[19,44,227]$.

\section{Conclusions and Future Perspectives}

This review provides a comprehensive analysis of mechanisms behind metabolic alterations conferring resistance to anticancer drugs and highlighting the reprogramming of tumor metabolism using metabolic inhibitors to sensitize cancer to cytotoxic drugs. A better understanding of metabolic characteristics and the molecular classification of $\mathrm{BC}$ helps to redefine the therapeutic approach. A primary challenge in targeting tumor metabolism for cancer treatment is changing the metabolic characteristics of a tumor during its progression and plasticity of cancer cell to switch between alternative pathways for energy, survival, and inhibition of apoptosis [228]. Additionally, in many cases, during targeting terminally differentiated cancerous cells, less abundant cancer stem cells are capable of evading the anticancer effect of the drug [229]. These cancer stem cells possess unique metabolic characteristics. They are capable of evading the immune response mechanisms and express essential transporter proteins that support multidrug resistance in addition to its ability to self-renew and differentiate into tumor progenitor cells, which then promotes cancer invasion, metastasis, and relapse [229]. Therefore, anticancer strategies must be efficient enough to target both terminally differentiated cancer cells and cancer stem cells [229]. Proteomic and metabolomic studies on tumor metabolism bring physicians closer to the successful identification of targets and hence a more effective clinical translation. Further research into tumor cell and cancer stem cell metabolism is warranted for overcoming the limitations in targeted therapy. The ongoing repurposing of drugs and the introduction of new candidate drugs that target tumor cell and cancer stem cell metabolism are promising research avenues and therefore deserve considerable attention.

Author Contributions: Conceptualization, E.V.; methodology, E.V., D.B., and S.M.S.; writing—original draft preparation, E.V.; writing-review and editing, E.V., D.B., S.M.S., P.K., A.L., and M.S.; visualization, E.V.; supervision, D.B.; project administration, D.B.; funding acquisition, D.B. All authors have read and agreed to the published version of the manuscript.

Funding: This work was made possible by the National Priorities Research Program grant (NPRP 11S-1214-170101; awarded to Professor Dietrich Büsselberg, June 2019-Current) from the Qatar National Research Fund (QNRF, a member of Qatar Foundation). The statements made herein are solely the responsibility of the authors.

Acknowledgments: The publication of this article was funded by the Weill Cornell Medicine-Qatar Distributed eLibrary.

Conflicts of Interest: The authors declare no conflict of interest. The funders had no role in the design of the study; in the collection, analyses, or interpretation of data; in the writing of the manuscript, or in the decision to publish the results. 


\section{Abbreviations}

\begin{tabular}{|c|c|}
\hline 2-DG & 2-Deoxy-D-glucose \\
\hline 3-BrPy & 3-bromopyruvate \\
\hline 3-PO & 3-(3-pyridinyl)-1-(4-pyridinyl)-2-propen-1-one \\
\hline $6-\mathrm{AN}$ & 6-aminonicotinamide \\
\hline AKT & Protein kinase B \\
\hline AMPK & $5^{\prime}$ adenosine monophosphate-activated protein kinase \\
\hline ASCT2 & Alanine-, serine-, cysteine transporter 2 \\
\hline ATO & Arsenic trioxide \\
\hline ATP & Adenosine triphosphate \\
\hline $\mathrm{BC}$ & Breast cancer \\
\hline $\mathrm{BSO}$ & Buthionine sulfoximine \\
\hline $\mathrm{CHC}$ & $\alpha$-cyano-4-hydroxycinnamate \\
\hline DCA & Dichloroacetate \\
\hline ECM & Extracellular matrix \\
\hline EGFR & Epidermal growth factor receptor \\
\hline EN & Enolase \\
\hline ER & Estrogen receptor \\
\hline GAPDH & Glyceraldehyde-3-phosphate dehydrogenase \\
\hline GLUT & Glucose transporter \\
\hline HIF- $1 \alpha$ & Hypoxia inducible factor alpha \\
\hline HK & Hexokinase \\
\hline HSF1 & Heat shock factor 1 \\
\hline $\mathrm{IC}_{50}$ & Half maximal inhibitory concentration \\
\hline IGFR & Insulin-like growth factor receptor \\
\hline LDHA & Lactate Dehydrogenase A \\
\hline MCP & Mitochondrial pyruvate carrier \\
\hline MCT1 & Monocarboxylate transporter 1 \\
\hline MDR & Multidrug resistance \\
\hline MET & Mesenchymal-epithelial transition factor \\
\hline OCT4 & Octamer binding transcription factor/protein 4 \\
\hline P-gp & Permeability glycoprotein \\
\hline PAMAM-PTX & Paclitaxel-conjugated polyamidoamine \\
\hline PDTC & Pyrrolidine dithiocarbamate \\
\hline PFK & Phosphofructokinase \\
\hline PFKFB3 & 6-phosphofructo-2-kinase/fructose-2, 6-bisphosphatase 3 \\
\hline PI3K & Phosphatidylinositol 3-kinase \\
\hline PK & Pyruvate kinase \\
\hline PPP & Pentose phosphate pathway \\
\hline Ras & Rat sarcoma viral proto-oncogene \\
\hline ROS & Reactive oxygen species \\
\hline RTK & Receptor tyrosine kinase \\
\hline SOX2 & Sex determining region $\mathrm{Y}$ Box 2 \\
\hline TCA & Tricarboxylic acid cycle \\
\hline TNBC & Triple negative breast cancer \\
\hline UA & Ursolic acid \\
\hline $\operatorname{VEGF} \alpha$ & Vascular endothelial growth factor alpha \\
\hline WT & Wildtype \\
\hline
\end{tabular}

\section{References}

1. Bray, F.; Ferlay, J.; Soerjomataram, I.; Siegel, R.L.; Torre, L.A.; Jemal, A. Global cancer statistics 2018: GLOBOCAN estimates of incidence and mortality worldwide for 36 cancers in 185 countries. CA Cancer J. Clin. 2018, 68, 394-424. [CrossRef] [PubMed] 
2. Kim, J.; DeBerardinis, R.J. Mechanisms and Implications of Metabolic Heterogeneity in Cancer. Cell Metab. 2019, 30, 434-446. [CrossRef]

3. American Cancer Society. Breast Cancer Facts \& Figures 2019-2020; American Cancer Society, Inc.: Atlanta, GA, USA, 2019.

4. DeMichele, A.; Yee, D.; Esserman, L. Mechanisms of Resistance to Neoadjuvant Chemotherapy in Breast Cancer. N. Engl. J. Med. 2017, 377, 2287-2289. [CrossRef]

5. Mayor, S. Side-effects of cancer drugs are under-reported in trials. Lancet Oncol. 2015, 16, e107. [CrossRef]

6. Mansoori, B.; Mohammadi, A.; Davudian, S.; Shirjang, S.; Baradaran, B. The Different Mechanisms of Cancer Drug Resistance: A Brief Review. Adv. Pharm. Bull. 2017, 7, 339-348. [CrossRef] [PubMed]

7. Calaf, G.M.; Zepeda, A.B.; Castillo, R.L.; Figueroa, C.A.; Arias, C.; Figueroa, E.; Farias, J.G. Molecular aspects of breast cancer resistance to drugs (Review). Int. J. Oncol. 2015, 47, 437-445. [CrossRef]

8. Jia, D.; Park, J.H.; Jung, K.H.; Levine, H.; Kaipparettu, B.A. Elucidating the Metabolic Plasticity of Cancer: Mitochondrial Reprogramming and Hybrid Metabolic States. Cells 2018, 7, 21. [CrossRef]

9. Lyon, R.C.; Cohen, J.S.; Faustino, P.J.; Megnin, F.; Myers, C.E. Glucose metabolism in drug-sensitive and drug-resistant human breast cancer cells monitored by magnetic resonance spectroscopy. Cancer Res. 1988, 48, 870-877.

10. Warburg, O. The Metabolism of Carcinoma Cells. J. Cancer Res. 1925, 9, 148. [CrossRef]

11. Liberti, M.V.; Locasale, J.W. The Warburg Effect: How Does it Benefit Cancer Cells? Trends Biochem. Sci. 2016, 41, 211-218. [CrossRef]

12. Haque, M.M.; Desai, K.V. Pathways to Endocrine Therapy Resistance in Breast Cancer. Front. Endocrinol. 2019, 10, 573. [CrossRef] [PubMed]

13. Ma, L.; Zong, X. Metabolic Symbiosis in Chemoresistance: Refocusing the Role of Aerobic Glycolysis. Front. Oncol. 2020, 10, 5. [CrossRef] [PubMed]

14. Varghese, E.; Samuel, S.M.; Abotaleb, M.; Cheema, S.; Mamtani, R.; Busselberg, D. The "Yin and Yang" of Natural Compounds in Anticancer Therapy of Triple-Negative Breast Cancers. Cancers 2018, 10, 346. [CrossRef]

15. Turashvili, G.; Brogi, E. Tumor Heterogeneity in Breast Cancer. Front. Med. 2017, 4, 227. [CrossRef] [PubMed]

16. Subbiah, S.; Gopu, G.; Senthilkumar, P.; Muniasamy, P. Molecular subtypes as a predictor of response to neoadjuvant chemotherapy in breast cancer patients. Indian J. Cancer 2017, 54, 652-657. [CrossRef]

17. Lehmann, B.D.; Bauer, J.A.; Chen, X.; Sanders, M.E.; Chakravarthy, A.B.; Shyr, Y.; Pietenpol, J.A. Identification of human triple-negative breast cancer subtypes and preclinical models for selection of targeted therapies. J. Clin. Investig. 2011, 121, 2750-2767. [CrossRef] [PubMed]

18. Abramson, V.G.; Mayer, I.A. Molecular Heterogeneity of Triple Negative Breast Cancer. Curr. Breast Cancer Rep. 2014, 6, 154-158. [CrossRef]

19. Cappelletti, V.; Iorio, E.; Miodini, P.; Silvestri, M.; Dugo, M.; Daidone, M.G. Metabolic Footprints and Molecular Subtypes in Breast Cancer. Dis. Markers 2017, 2017, 7687851. [CrossRef]

20. Lin, J.; Xia, L.; Liang, J.; Han, Y.; Wang, H.; Oyang, L.; Tan, S.; Tian, Y.; Rao, S.; Chen, X.; et al. The roles of glucose metabolic reprogramming in chemo- and radio-resistance. J. Exp. Clin. Cancer Res. 2019, 38, 218. [CrossRef]

21. Dai, X.; Li, T.; Bai, Z.; Yang, Y.; Liu, X.; Zhan, J.; Shi, B. Breast cancer intrinsic subtype classification, clinical use and future trends. Am. J. Cancer Res. 2015, 5, 2929-2943.

22. Esechie, A.; Du, G. Increased lipogenesis in cancer. Commun. Integr. Biol. 2009, 2, 545-548. [CrossRef]

23. Villa, E.; Ali, E.S.; Sahu, U.; Ben-Sahra, I. Cancer Cells Tune the Signaling Pathways to Empower de Novo Synthesis of Nucleotides. Cancers 2019, 11, 688. [CrossRef] [PubMed]

24. Samuel, S.M.; Varghese, E.; Varghese, S.; Büsselberg, D. Challenges and perspectives in the treatment of diabetes associated breast cancer. Cancer Treat. Rev. 2018, 70, 98-111. [CrossRef] [PubMed]

25. Costello, L.C.; Franklin, R.B. 'Why do tumour cells glycolyse?': From glycolysis through citrate to lipogenesis. Mol. Cell. Biochem. 2005, 280, 1-8. [CrossRef]

26. Mattaini, K.R.; Sullivan, M.R.; Vander Heiden, M.G. The importance of serine metabolism in cancer. J. Cell Biol. 2016, 214, 249-257. [CrossRef]

27. Moreadith, R.W.; Lehninger, A.L. The pathways of glutamate and glutamine oxidation by tumor cell mitochondria. Role of mitochondrial NAD(P)+-dependent malic enzyme. J. Biol. Chem. 1984, 259, 6215-6221. 
28. Zhou, Z.; Ibekwe, E.; Chornenkyy, Y. Metabolic Alterations in Cancer Cells and the Emerging Role of Oncometabolites as Drivers of Neoplastic Change. Antioxidants 2018, 7, 16. [CrossRef]

29. Amelio, I.; Cutruzzolá, F.; Antonov, A.; Agostini, M.; Melino, G. Serine and glycine metabolism in cancer. Trends Biochem. Sci. 2014, 39, 191-198. [CrossRef]

30. Zhang, F.; Du, G. Dysregulated lipid metabolism in cancer. World J. Biol. Chem. 2012, 3, 167-174. [CrossRef]

31. Koundouros, N.; Poulogiannis, G. Reprogramming of fatty acid metabolism in cancer. Br. J. Cancer 2020, 122, 4-22. [CrossRef]

32. Kim, S.; Kim, D.H.; Jung, W.H.; Koo, J.S. Succinate dehydrogenase expression in breast cancer. Springerplus 2013, 2, 299. [CrossRef]

33. Lim, S.-O.; Li, C.-W.; Xia, W.; Lee, H.-H.; Chang, S.-S.; Shen, J.; Hsu, J.L.; Raftery, D.; Djukovic, D.; Gu, H.; et al. EGFR Signaling Enhances Aerobic Glycolysis in Triple-Negative Breast Cancer Cells to Promote Tumor Growth and Immune Escape. Cancer Res. 2016, 76, 1284-1296. [CrossRef]

34. Varghese, S.; Samuel, S.M.; Varghese, E.; Kubatka, P.; Busselberg, D. High Glucose Represses the AntiProliferative and Pro-Apoptotic Effect of Metformin in Triple Negative Breast Cancer Cells. Biomolecules 2019, 9, 16. [CrossRef] [PubMed]

35. Liu, X.; Miao, W.; Huang, M.; Li, L.; Dai, X.; Wang, Y. Elevated Hexokinase II Expression Confers Acquired Resistance to 4-Hydroxytamoxifen in Breast Cancer Cells. Mol. Cell. Proteom. 2019, 18, 2273-2284. [CrossRef] [PubMed]

36. Tu, S.-H.; Chang, C.-C.; Chen, C.-S.; Tam, K.-W.; Wang, Y.-J.; Lee, C.-H.; Lin, H.-W.; Cheng, T.-C.; Huang, C.-S.; $\mathrm{Chu}$, J.-S.; et al. Increased expression of enolase $\alpha$ in human breast cancer confers tamoxifen resistance in human breast cancer cells. Breast Cancer Res. Treat. 2010, 121, 539-553. [CrossRef] [PubMed]

37. Sato-Tadano, A.; Suzuki, T.; Amari, M.; Takagi, K.; Miki, Y.; Tamaki, K.; Watanabe, M.; Ishida, T.; Sasano, H.; Ohuchi, N. Hexokinase II in breast carcinoma: A potent prognostic factor associated with hypoxia-inducible factor-1a and Ki-67. Cancer Sci. 2013, 104, 1380-1388. [CrossRef]

38. Zancan, P.; Sola-Penna, M.; Furtado, C.M.; Da Silva, D. Differential expression of phosphofructokinase-1 isoforms correlates with the glycolytic efficiency of breast cancer cells. Mol. Genet. Metab. 2010, 100, 372-378. [CrossRef] [PubMed]

39. Sun, X.; Wang, M.; Wang, M.; Yu, X.; Guo, J.; Sun, T.; Li, X.; Yao, L.; Dong, H.; Xu, Y. Metabolic Reprogramming in Triple-Negative Breast Cancer. Front. Oncol. 2020, 10, 428. [CrossRef]

40. Pucci-Minafra, I.; Fontana, S.; Cancemi, P.; Alaimo, G.; Minafra, S. Proteomic Patterns of Cultured Breast Cancer Cells and Epithelial Mammary Cells. Ann. N. Y. Acad. Sci. 2002, 963, 122-139. [CrossRef]

41. Altenberg, B.; Greulich, K.O. Genes of glycolysis are ubiquitously overexpressed in 24 cancer classes. Genomics 2004, 84, 1014-1020. [CrossRef]

42. Cerella, C.; Radogna, F.; Dicato, M.; Diederich, M. Natural compounds as regulators of the cancer cell metabolism. Int. J. Cell Biol. 2013, 2013, 639401. [CrossRef]

43. Gao, J.-L.; Chen, Y.-G. Natural compounds regulate glycolysis in hypoxic tumor microenvironment. BioMed Res. Int. 2015, 2015, 354143. [CrossRef]

44. Rivenzon-Segal, D.; Boldin-Adamsky, S.; Seger, D.; Seger, R.; Degani, H. Glycolysis and glucose transporter 1 as markers of response to hormonal therapy in breast cancer. Int. J. Cancer 2003, 107, 177-182. [CrossRef] [PubMed]

45. Samuel, S.M.; Varghese, E.; Kubatka, P.; Triggle, C.R.; Büsselberg, D. Metformin: The Answer to Cancer in a Flower? Current Knowledge and Future Prospects of Metformin as an Anti-Cancer Agent in Breast Cancer. Biomolecules 2019, 9, 846. [CrossRef] [PubMed]

46. Wahdan-Alaswad, R.S.; Edgerton, S.M.; Salem, H.S.; Thor, A.D. Metformin Targets Glucose Metabolism in Triple Negative Breast Cancer. J. Oncol. Transl. Res. 2018, 4. [CrossRef]

47. Yang, Y.; Wolfram, J.; Boom, K.; Fang, X.; Shen, H.; Ferrari, M. Hesperetin impairs glucose uptake and inhibits proliferation of breast cancer cells. Cell Biochem. Funct. 2013, 31, 374-379. [CrossRef]

48. Azevedo, C.; Correia-Branco, A.; Araújo, J.R.; Guimarães, J.T.; Keating, E.; Martel, F. The chemopreventive effect of the dietary compound kaempferol on the MCF-7 human breast cancer cell line is dependent on inhibition of glucose cellular uptake. Nutr. Cancer 2015, 67, 504-513. [CrossRef]

49. Wei, R.; Mao, L.; Xu, P.; Zheng, X.; Hackman, R.M.; Mackenzie, G.G.; Wang, Y. Suppressing glucose metabolism with epigallocatechin-3-gallate (EGCG) reduces breast cancer cell growth in preclinical models. Food Funct. 2018, 9, 5682-5696. [CrossRef] 
50. Granchi, C.; Fortunato, S.; Minutolo, F. Anticancer agents interacting with membrane glucose transporters. MedChem Comm 2016, 7, 1716-1729. [CrossRef]

51. Catanzaro, D.; Gabbia, D.; Cocetta, V.; Biagi, M.; Ragazzi, E.; Montopoli, M.; Carrara, M. Silybin counteracts doxorubicin resistance by inhibiting GLUT1 expression. Fitoterapia 2018, 124, 42-48. [CrossRef]

52. Levenson, A.S.; Thurn, T.E.; Simons, L.A.; Osipo, C.; Jordan, V.C.; Satcher, R.L.; Gartenhaus, R.B. Overexpression of MCT1 oncogene contributes to increased tumorigenicity of MCF7 breast cancer cells. Cancer Res. 2005, 65, 662. [CrossRef] [PubMed]

53. Filipa, M.-S.; Vera, M.-G.; Sílvia, P.; André, F.V.; Joana, P.; Fernando, C.S.; Fátima, B.; Céline, P. Differential sensitivities to lactate transport inhibitors of breast cancer cell lines. Endocr. Relat. Cancer 2014, 21, 27-38. [CrossRef]

54. Marini, C.; Salani, B.; Massollo, M.; Amaro, A.; Esposito, A.I.; Maria Orengo, A.; Capitanio, S.; Emionite, L.; Riondato, M.; Bottoni, G.; et al. Direct inhibition of hexokinase activity by metformin at least partially impairs glucose metabolism and tumor growth in experimental breast cancer. Cell Cycle 2013, 12, 3490-3499. [CrossRef] [PubMed]

55. Aft, R.L.; Zhang, F.W.; Gius, D. Evaluation of 2-deoxy-D-glucose as a chemotherapeutic agent: Mechanism of cell death. Br. J. Cancer 2002, 87, 805-812. [CrossRef]

56. O'Neal, J.; Clem, A.; Reynolds, L.; Dougherty, S.; Imbert-Fernandez, Y.; Telang, S.; Chesney, J.; Clem, B.F. Inhibition of 6-phosphofructo-2-kinase (PFKFB3) suppresses glucose metabolism and the growth of HER2+ breast cancer. Breast Cancer Res. Treat. 2016, 160, 29-40. [CrossRef]

57. Shi, L.; Pan, H.; Liu, Z.; Xie, J.; Han, W. Roles of PFKFB3 in cancer. Signal Transduct. Target. Ther. 2017, 2, 17044. [CrossRef]

58. Ganapathy-Kanniappan, S.; Kunjithapatham, R.; Geschwind, J.F. Anticancer efficacy of the metabolic blocker 3-bromopyruvate: Specific molecular targeting. Anticancer Res. 2013, 33, 13-20.

59. Fan, T.; Sun, G.; Sun, X.; Zhao, L.; Zhong, R.; Peng, Y. Tumor Energy Metabolism and Potential of 3-Bromopyruvate as an Inhibitor of Aerobic Glycolysis: Implications in Tumor Treatment. Cancers 2019, 11, 317. [CrossRef]

60. Chen, J.; Hu, X.; Cui, J. Shikonin, vitamin K3 and vitamin K5 inhibit multiple glycolytic enzymes in MCF-7 cells. Oncol. Lett. 2018, 15, 7423-7432. [CrossRef]

61. Li, W.; Liu, J.; Jackson, K.; Shi, R.; Zhao, Y. Sensitizing the therapeutic efficacy of taxol with shikonin in human breast cancer cells. PLoS ONE 2014, 9, e94079. [CrossRef]

62. Zhou, M.; Zhao, Y.; Ding, Y.; Liu, H.; Liu, Z.; Fodstad, O.; Riker, A.I.; Kamarajugadda, S.; Lu, J.; Owen, L.B.; et al. Warburg effect in chemosensitivity: Targeting lactate dehydrogenase-A re-sensitizes taxol-resistant cancer cells to taxol. Mol. Cancer 2010, 9, 33. [CrossRef]

63. Wang, S.; Xie, J.; Li, J.; Liu, F.; Wu, X.; Wang, Z. Cisplatin suppresses the growth and proliferation of breast and cervical cancer cell lines by inhibiting integrin beta5-mediated glycolysis. Am. J. Cancer Res. 2016, 6, 1108-1117. [PubMed]

64. Bai, X.; Jiang, H.; Han, G.; He, Q. Chidamide suppresses the glycolysis of triple negative breast cancer cells partially by targeting the miR-33a-5p-LDHA axis. Mol. Med. Rep. 2019, 20, 1857-1865. [CrossRef] [PubMed]

65. Lu, H.; Li, X.; Luo, Z.; Liu, J.; Fan, Z. Cetuximab reverses the Warburg effect by inhibiting HIF-1-regulated LDH-A. Mol. Cancer Ther. 2013, 12, 2187-2199. [CrossRef]

66. Sun, R.C.; Board, P.G.; Blackburn, A.C. Targeting metabolism with arsenic trioxide and dichloroacetate in breast cancer cells. Mol. Cancer 2011, 10, 142. [CrossRef] [PubMed]

67. Andrzejewski, S.; Gravel, S.P.; Pollak, M.; St-Pierre, J. Metformin directly acts on mitochondria to alter cellular bioenergetics. Cancer Metab. 2014, 2, 12. [CrossRef]

68. Sun, R.C.; Fadia, M.; Dahlstrom, J.E.; Parish, C.R.; Board, P.G.; Blackburn, A.C. Reversal of the glycolytic phenotype by dichloroacetate inhibits metastatic breast cancer cell growth in vitro and in vivo. Breast Cancer Res. Treat. 2010, 120, 253-260. [CrossRef]

69. Verma, A.; Lam, Y.M.; Leung, Y.C.; Hu, X.; Chen, X.; Cheung, E.; Tam, K.Y. Combined use of arginase and dichloroacetate exhibits anti-proliferative effects in triple negative breast cancer cells. J. Pharm. Pharmacol. 2019, 71, 306-315. [CrossRef]

70. Mobasheri, A.; Richardson, S.; Mobasheri, R.; Shakibaei, M.; Hoyland, J.A. Hypoxia inducible factor-1 and facilitative glucose transporters GLUT1 and GLUT3: Putative molecular components of the oxygen and glucose sensing apparatus in articular chondrocytes. Histol. Histopathol. 2005, 20, 1327-1338. [CrossRef] 
71. Krzeslak, A.; Wojcik-Krowiranda, K.; Forma, E.; Jozwiak, P.; Romanowicz, H.; Bienkiewicz, A.; Brys, M. Expression of GLUT1 and GLUT3 Glucose Transporters in Endometrial and Breast Cancers. Pathol. Oncol. Res. 2012, 18, 721-728. [CrossRef]

72. Robey, I.F.; Lien, A.D.; Welsh, S.J.; Baggett, B.K.; Gillies, R.J. Hypoxia-inducible factor-1alpha and the glycolytic phenotype in tumors. Neoplasia 2005, 7, 324-330. [CrossRef] [PubMed]

73. Bos, R.; van Der Hoeven, J.J.; van Der Wall, E.; van Der Groep, P.; van Diest, P.J.; Comans, E.F.; Joshi, U.; Semenza, G.L.; Hoekstra, O.S.; Lammertsma, A.A.; et al. Biologic correlates of (18)fluorodeoxyglucose uptake in human breast cancer measured by positron emission tomography. J. Clin. Oncol. 2002, 20, 379-387. [CrossRef] [PubMed]

74. Hamilton, K.E.; Rekman, J.F.; Gunnink, L.K.; Busscher, B.M.; Scott, J.L.; Tidball, A.M.; Stehouwer, N.R.; Johnecheck, G.N.; Looyenga, B.D.; Louters, L.L. Quercetin inhibits glucose transport by binding to an exofacial site on GLUT1. Biochimie 2018, 151, 107-114. [CrossRef] [PubMed]

75. Pérez, A.; Ojeda, P.; Ojeda, L.; Salas, M.; Rivas, C.I.; Vera, J.C.; Reyes, A.M. Hexose transporter GLUT1 harbors several distinct regulatory binding sites for flavones and tyrphostins. Biochemistry 2011, 50, 8834-8845. [CrossRef]

76. Liu, Y.; Cao, Y.; Zhang, W.; Bergmeier, S.; Qian, Y.; Akbar, H.; Colvin, R.; Ding, J.; Tong, L.; Wu, S.; et al. A small-molecule inhibitor of glucose transporter 1 downregulates glycolysis, induces cell-cycle arrest, and inhibits cancer cell growth in vitro and in vivo. Mol. Cancer Ther. 2012, 11, 1672-1682. [CrossRef]

77. Zambrano, A.; Molt, M.; Uribe, E.; Salas, M. Glut 1 in Cancer Cells and the Inhibitory Action of Resveratrol as A Potential Therapeutic Strategy. Int. J. Mol. Sci. 2019, 20, 3374. [CrossRef]

78. Sawayama, H.; Ogata, Y.; Ishimoto, T.; Mima, K.; Hiyoshi, Y.; Iwatsuki, M.; Baba, Y.; Miyamoto, Y.; Yoshida, N.; Baba, H. Glucose transporter 1 regulates the proliferation and cisplatin sensitivity of esophageal cancer. Cancer Sci. 2019, 110, 1705-1714. [CrossRef]

79. Mathupala, S.; Parajuli, P.; Sloan, A. Silencing of monocarboxylate transporters via small interfering ribonucleic acid inhibits glycolysis and induces cell death in malignant glioma: An in vitro study. Neurosurgery 2004, 55, 1410-1419. [CrossRef]

80. Gallagher, S.; Castorino, J.; Wang, D.; Philp, N. Monocarboxylate transporter 4 regulates maturation and trafficking of CD147 to the plasma membrane in the metastatic breast cancer cell line MDA-MB-231. Cancer Res. 2007, 67, 4182-4189. [CrossRef]

81. Baltazar, F.; Pinheiro, C.; Morais-Santos, F.; Azevedo-Silva, J.; Queirós, O.; Preto, A.; Casal, M. Monocarboxylate transporters as targets and mediators in cancer therapy response. Histol. Histopathol. 2014, 29, 1511-1524. [CrossRef]

82. Ullah, M.S.; Davies, A.J.; Halestrap, A.P. The plasma membrane lactate transporter MCT4, but not MCT1, is up-regulated by hypoxia through a HIF-1alpha-dependent mechanism. J. Biol. Chem. 2006, 281, 9030-9037. [CrossRef] [PubMed]

83. Hong, C.S.; Graham, N.A.; Gu, W.; Espindola Camacho, C.; Mah, V.; Maresh, E.L.; Alavi, M.; Bagryanova, L.; Krotee, P.A.L.; Gardner, B.K.; et al. MCT1 Modulates Cancer Cell Pyruvate Export and Growth of Tumors that Co-express MCT1 and MCT4. Cell Rep. 2016, 14, 1590-1601. [CrossRef] [PubMed]

84. Johnson, J.M.; Cotzia, P.; Fratamico, R.; Mikkilineni, L.; Chen, J.; Colombo, D.; Mollaee, M.; Whitaker-Menezes, D.; Domingo-Vidal, M.; Lin, Z.; et al. MCT1 in Invasive Ductal Carcinoma: Monocarboxylate Metabolism and Aggressive Breast Cancer. Front. Cell Dev. Biol. 2017, 5, 27. [CrossRef]

85. Leung, Y.H.; Belanger, F.; Lu, J.; Turgeon, J.; Michaud, V. Effects of a Series of Acidic Drugs on L-Lactic Acid Transport by the Monocarboxylate Transporters MCT1 and MCT4. Curr. Pharm. Biotechnol. 2017, 18, 1141-1150. [CrossRef] [PubMed]

86. Liu, H.; Ertay, A.; Peng, P.; Li, J.; Liu, D.; Xiong, H.; Zou, Y.; Qiu, H.; Hancock, D.; Yuan, X.; et al. SGLT1 is required for the survival of triple-negative breast cancer cells via potentiation of EGFR activity. Mol. Oncol. 2019, 13, 1874-1886. [CrossRef]

87. Gottlob, K.; Majewski, N.; Kennedy, S.; Kandel, E.; Robey, R.B.; Hay, N. Inhibition of early apoptotic events by Akt/PKB is dependent on the first committed step of glycolysis and mitochondrial hexokinase. Genes Dev. 2001, 15, 1406-1418. [CrossRef]

88. Ahn, K.J.; Hwang, H.S.; Park, J.H.; Bang, S.H.; Kang, W.J.; Yun, M.; Lee, J.D. Evaluation of the role of hexokinase type II in cellular proliferation and apoptosis using human hepatocellular carcinoma cell lines. J. Nucl. Med. 2009, 50, 1525-1532. [CrossRef] 
89. Ling, S.; Song, L.; Fan, N.; Feng, T.; Liu, L.; Yang, X.; Wang, M.; Li, Y.; Tian, Y.; Zhao, F.; et al. Combination of metformin and sorafenib suppresses proliferation and induces autophagy of hepatocellular carcinoma via targeting the mTOR pathway. Int. J. Oncol. 2017, 50, 297-309. [CrossRef]

90. Wick, A.N.; Drury, D.R.; Nakada, H.I.; Wolfe, J.B. Localization of the primary metabolic block produced by 2-deoxyglucose. J. Biol. Chem. 1957, 224, 963-969.

91. Yang, Q.; Zhang, T.; Wang, C.; Jiao, J.; Li, J.; Deng, Y. Coencapsulation of epirubicin and metformin in PEGylated liposomes inhibits the recurrence of murine sarcoma S180 existing CD133+ cancer stem-like cells. Eur. J. Pharm. Biopharm. 2014, 88, 737-745. [CrossRef]

92. Zhang, T.; Zhu, X.; Wu, H.; Jiang, K.; Zhao, G.; Shaukat, A.; Deng, G.; Qiu, C. Targeting the ROS/PI3K/ $\mathrm{AKT} / \mathrm{HIF}-1 \alpha / \mathrm{HK} 2$ axis of breast cancer cells: Combined administration of Polydatin and 2-Deoxy-d-glucose. J. Cell. Mol. Med. 2019, 23, 3711-3723. [CrossRef] [PubMed]

93. Bizjak, M.; Malavašič, P.; Dolinar, K.; Pohar, J.; Pirkmajer, S.; Pavlin, M. Combined treatment with Metformin and 2-deoxy glucose induces detachment of viable MDA-MB-231 breast cancer cells in vitro. Sci. Rep. 2017, 7, 1761. [CrossRef] [PubMed]

94. Peng, F.; Li, Q.; Sun, J.Y.; Luo, Y.; Chen, M.; Bao, Y. PFKFB3 is involved in breast cancer proliferation, migration, invasion and angiogenesis. Int. J. Oncol. 2018, 52, 945-954. [CrossRef] [PubMed]

95. Ganapathy-Kanniappan, S. Evolution of GAPDH as a druggable target of tumor glycolysis? Expert Opin. Ther. Targets 2018, 22, 295-298. [CrossRef]

96. Huang, X.; Li, X.; Xie, X.; Ye, F.; Chen, B.; Song, C.; Tang, H.; Xie, X. High expressions of LDHA and AMPK as prognostic biomarkers for breast cancer. Breast 2016, 30, 39-46. [CrossRef]

97. Pelizzari, G.; Basile, D.; Zago, S.; Lisanti, C.; Bartoletti, M.; Bortot, L.; Vitale, M.G.; Fanotto, V.; Barban, S.; Cinausero, M.; et al. Lactate Dehydrogenase (LDH) Response to First-Line Treatment Predicts Survival in Metastatic Breast Cancer: First Clues for A Cost-Effective and Dynamic Biomarker. Cancers 2019, 11, 1243. [CrossRef]

98. Farabegoli, F.; Vettraino, M.; Manerba, M.; Fiume, L.; Roberti, M.; Di Stefano, G. Galloflavin, a new lactate dehydrogenase inhibitor, induces the death of human breast cancer cells with different glycolytic attitude by affecting distinct signaling pathways. Eur. J. Pharm. Sci. 2012, 47, 729-738. [CrossRef]

99. Jia, L.; Huang, S.; Yin, X.; Zan, Y.; Guo, Y.; Han, L. Quercetin suppresses the mobility of breast cancer by suppressing glycolysis through Akt-mTOR pathway mediated autophagy induction. Life Sci. 2018, 208, 123-130. [CrossRef]

100. Fan, K.; Fan, Z.; Cheng, H.; Huang, Q.; Yang, C.; Jin, K.; Luo, G.; Yu, X.; Liu, C. Hexokinase 2 dimerization and interaction with voltage-dependent anion channel promoted resistance to cell apoptosis induced by gemcitabine in pancreatic cancer. Cancer Med. 2019, 8, 5903-5915. [CrossRef]

101. Guo, Y.; Wei, L.; Zhou, Y.; Lu, N.; Tang, X.; Li, Z.; Wang, X. Flavonoid GL-V9 induces apoptosis and inhibits glycolysis of breast cancer via disrupting GSK-3 $\beta$-modulated mitochondrial binding of HKII. Free Radic. Biol. Med. 2020, 146, 119-129. [CrossRef]

102. Zhou, Y.; Lu, N.; Qiao, C.; Ni, T.; Li, Z.; Yu, B.; Guo, Q.; Wei, L. FV-429 induces apoptosis and inhibits glycolysis by inhibiting Akt-mediated phosphorylation of hexokinase II in MDA-MB-231 cells. Mol. Carcinog. 2016, 55, 1317-1328. [CrossRef] [PubMed]

103. Al Tameemi, W.; Dale, T.P.; Al-Jumaily, R.M.K.; Forsyth, N.R. Hypoxia-Modified Cancer Cell Metabolism. Front. Cell Dev. Biol. 2019, 7, 4. [CrossRef] [PubMed]

104. Lee, M.; Yoon, J.-H. Metabolic interplay between glycolysis and mitochondrial oxidation: The reverse Warburg effect and its therapeutic implication. World J. Biol. Chem. 2015, 6, 148-161. [CrossRef] [PubMed]

105. Florea, A.M.; Büsselberg, D. Arsenic trioxide in environmentally and clinically relevant concentrations interacts with calcium homeostasis and induces cell type specific cell death in tumor and non-tumor cells. Toxicol. Lett. 2008, 179, 34-42. [CrossRef]

106. Liu, C.; Wang, X.; Zhang, Y. The Roles of HK2 on Tumorigenesis of Cervical Cancer. Technol. Cancer Res. Treat. 2019, 18. [CrossRef]

107. Siu, M.K.Y.; Jiang, Y.-X.; Wang, J.-J.; Leung, T.H.Y.; Han, C.Y.; Tsang, B.K.; Cheung, A.N.Y.; Ngan, H.Y.S.; Chan, K.K.L. Hexokinase 2 Regulates Ovarian Cancer Cell Migration, Invasion and Stemness via FAK/ERK1/ 2/MMP9/NANOG/SOX9 Signaling Cascades. Cancers 2019, 11, 813. [CrossRef] 
108. Yang, T.; Ren, C.; Qiao, P.; Han, X.; Wang, L.; Lv, S.; Sun, Y.; Liu, Z.; Du, Y.; Yu, Z. PIM2-mediated phosphorylation of hexokinase 2 is critical for tumor growth and paclitaxel resistance in breast cancer. Oncogene 2018, 37, 5997-6009. [CrossRef]

109. Atsumi, T.; Chesney, J.; Metz, C.; Leng, L.; Donnelly, S.; Makita, Z.; Mitchell, R.; Bucala, R. High expression of inducible 6-phosphofructo-2-kinase/fructose-2,6-bisphosphatase (iPFK-2; PFKFB3) in human cancers. Cancer Res. 2002, 62, 5881-5887.

110. Klarer, A.C.; O’Neal, J.; Imbert-Fernandez, Y.; Clem, A.; Ellis, S.R.; Clark, J.; Clem, B.; Chesney, J.; Telang, S. Inhibition of 6-phosphofructo-2-kinase (PFKFB3) induces autophagy as a survival mechanism. Cancer Metab. 2014, 2, 2. [CrossRef]

111. Mondal, S.; Roy, D.; Sarkar Bhattacharya, S.; Jin, L.; Jung, D.; Zhang, S.; Kalogera, E.; Staub, J.; Wang, Y.; Xuyang, W.; et al. Therapeutic targeting of PFKFB3 with a novel glycolytic inhibitor PFK158 promotes lipophagy and chemosensitivity in gynecologic cancers. Int. J. Cancer 2019, 144, 178-189. [CrossRef]

112. Zhang, L.; Wang, H.; Dong, X. Diagnostic value of $\alpha$-enolase expression and serum $\alpha$-enolase autoantibody levels in lung cancer. J. Bras. Pneumol. 2018, 44, 18-23. [CrossRef] [PubMed]

113. Cancemi, P.; Buttacavoli, M.; Roz, E.; Feo, S. Expression of Alpha-Enolase (ENO1), Myc Promoter-Binding Protein-1 (MBP-1) and Matrix Metalloproteinases (MMP-2 and MMP-9) Reflect the Nature and Aggressiveness of Breast Tumors. Int. J. Mol. Sci. 2019, 20, 3952. [CrossRef] [PubMed]

114. Capello, M.; Ferri-Borgogno, S.; Riganti, C.; Chattaragada, M.S.; Principe, M.; Roux, C.; Zhou, W.; Petricoin, E.F.; Cappello, P.; Novelli, F. Targeting the Warburg effect in cancer cells through ENO1 knockdown rescues oxidative phosphorylation and induces growth arrest. Oncotarget 2015, 7, 5598. [CrossRef] [PubMed]

115. Marcinkowska, M.; Stanczyk, M.; Janaszewska, A.; Sobierajska, E.; Chworos, A.; Klajnert-Maculewicz, B. Multicomponent Conjugates of Anticancer Drugs and Monoclonal Antibody with PAMAM Dendrimers to Increase Efficacy of HER-2 Positive Breast Cancer Therapy. Pharm. Res. 2019, 36, 154. [CrossRef] [PubMed]

116. Catanzaro, D.; Gaude, E.; Orso, G.; Giordano, C.; Guzzo, G.; Rasola, A.; Ragazzi, E.; Caparrotta, L.; Frezza, C.; Montopoli, M. Inhibition of glucose-6-phosphate dehydrogenase sensitizes cisplatin-resistant cells to death. Oncotarget 2015, 6, 30102-30114. [CrossRef]

117. Woo, Y.M.; Shin, Y.; Lee, E.J.; Lee, S.; Jeong, S.H.; Kong, H.K.; Park, E.Y.; Kim, H.K.; Han, J.; Chang, M.; et al. Inhibition of Aerobic Glycolysis Represses Akt/mTOR/HIF-1alpha Axis and Restores Tamoxifen Sensitivity in Antiestrogen-Resistant Breast Cancer Cells. PLoS ONE 2015, 10, e0132285. [CrossRef]

118. Israelsen, W.J.; Vander Heiden, M.G. Pyruvate kinase: Function, regulation and role in cancer. Semin. Cell Dev. Biol. 2015, 43, 43-51. [CrossRef]

119. Hsu, M.-C.; Hung, W.-C. Pyruvate kinase M2 fuels multiple aspects of cancer cells: From cellular metabolism, transcriptional regulation to extracellular signaling. Mol. Cancer 2018, 17, 35. [CrossRef]

120. Christofk, H.R.; Vander Heiden, M.G.; Harris, M.H.; Ramanathan, A.; Gerszten, R.E.; Wei, R.; Fleming, M.D.; Schreiber, S.L.; Cantley, L.C. The M2 splice isoform of pyruvate kinase is important for cancer metabolism and tumour growth. Nature 2008, 452, 230-233. [CrossRef]

121. Wu, J.; Hu, L.; Chen, M.; Cao, W.; Chen, H.; He, T. Pyruvate kinase M2 overexpression and poor prognosis in solid tumors of digestive system: Evidence from 16 cohort studies. Onco Targets Ther. 2016, 9, 4277-4288. [CrossRef]

122. Rzechonek, A.; Kaminska, A.; Mamczur, P.; Drapiewski, A.; Budzynski, W. Limited Clinical Significance of Dimeric Form of Pyruvate Kinase as a Diagnostic and Prognostic Biomarker in Non-small Cell Lung Cancer. Adv. Exp. Med. Biol. 2017, 955, 51-57. [CrossRef] [PubMed]

123. Lin, Y.; Liu, F.; Fan, Y.; Qian, X.; Lang, R.; Gu, F.; Gu, J.; Fu, L. Both high expression of pyruvate kinase M2 and vascular endothelial growth factor-C predicts poorer prognosis in human breast cancer. Int. J. Clin. Exp. Pathol. 2015, 8, 8028-8037. [PubMed]

124. Castagnoli, L.; Iorio, E.; Dugo, M.; Koschorke, A.; Faraci, S.; Canese, R.; Casalini, P.; Nanni, P.; Vernieri, C.; Di Nicola, M.; et al. Intratumor lactate levels reflect HER2 addiction status in HER2-positive breast cancer. J. Cell. Physiol. 2019, 234, 1768-1779. [CrossRef] [PubMed]

125. Yang, Y.; Wu, K.; Liu, Y.; Shi, L.; Tao, K.; Wang, G. Prognostic significance of metabolic enzyme pyruvate kinase M2 in breast cancer: A meta-analysis. Medicine 2017, 96, e8690. [CrossRef] [PubMed]

126. Lin, Y.; Lv, F.; Liu, F.; Guo, X.; Fan, Y.; Gu, F.; Gu, J.; Fu, L. High Expression of Pyruvate Kinase M2 is Associated with Chemosensitivity to Epirubicin and 5-Fluorouracil in Breast Cancer. J. Cancer 2015, 6, 1130-1139. [CrossRef] 
127. He, J.; Xie, G.; Tong, J.; Peng, Y.; Huang, H.; Li, J.; Wang, N.; Liang, H. Overexpression of microRNA-122 re-sensitizes 5-FU-resistant colon cancer cells to 5-FU through the inhibition of PKM2 in vitro and in vivo. Cell Biochem. Biophys. 2014, 70, 1343-1350. [CrossRef]

128. Su, Q.; Luo, S.; Tan, Q.; Deng, J.; Zhou, S.; Peng, M.; Tao, T.; Yang, X. The role of pyruvate kinase M2 in anticancer therapeutic treatments. Oncol. Lett. 2019, 18, 5663-5672. [CrossRef]

129. Qian, Y.; Bi, L.; Yang, Y.; Wang, D. Effect of pyruvate kinase M2-regulating aerobic glycolysis on chemotherapy resistance of estrogen receptor-positive breast cancer. Anticancer Drugs 2018, 29, 616-627. [CrossRef]

130. Yoo, B.C.; Ku, J.L.; Hong, S.H.; Shin, Y.K.; Park, S.Y.; Kim, H.K.; Park, J.G. Decreased pyruvate kinase M2 activity linked to cisplatin resistance in human gastric carcinoma cell lines. Int. J. Cancer 2004, 108, 532-539. [CrossRef]

131. Hou, X.M.; Yuan, S.Q.; Zhao, D.; Liu, X.J.; Wu, X.A. LDH-A promotes malignant behavior via activation of epithelial-to-mesenchymal transition in lung adenocarcinoma. Biosci. Rep. 2019, 39. [CrossRef]

132. Han, R.L.; Wang, F.P.; Zhang, P.A.; Zhou, X.Y.; Li, Y. miR-383 inhibits ovarian cancer cell proliferation, invasion and aerobic glycolysis by targeting LDHA. Neoplasma 2017, 64, 244-252. [CrossRef] [PubMed]

133. Rizwan, A.; Serganova, I.; Khanin, R.; Karabeber, H.; Ni, X.; Thakur, S.; Zakian, K.L.; Blasberg, R.; Koutcher, J.A. Relationships between LDH-A, lactate, and metastases in $4 \mathrm{~T} 1$ breast tumors. Clin. Cancer Res. Off. J. Am. Assoc. Cancer Res. 2013, 19, 5158-5169. [CrossRef] [PubMed]

134. Jin, L.; Chun, J.; Pan, C.; Alesi, G.N.; Li, D.; Magliocca, K.R.; Kang, Y.; Chen, Z.G.; Shin, D.M.; Khuri, F.R.; et al. Phosphorylation-mediated activation of LDHA promotes cancer cell invasion and tumour metastasis. Oncogene 2017, 36, 3797-3806. [CrossRef] [PubMed]

135. Das, C.K.; Parekh, A.; Parida, P.K.; Bhutia, S.K.; Mandal, M. Lactate dehydrogenase A regulates autophagy and tamoxifen resistance in breast cancer. Biochim. Biophys. Acta Mol. Cell Res. 2019, 1866, 1004-1018. [CrossRef] [PubMed]

136. Finn, R.S.; Martin, M.; Rugo, H.S.; Jones, S.E.; Im, S.A.; Gelmon, K.A.; Harbeck, N.; Lipatov, O.N.; Walshe, J.M.; Moulder, S.L.; et al. PALOMA-2: Primary results from a phase III trial of palbociclib (P) with letrozole (L) compared with letrozole alone in postmenopausal women with ER+/HER2- advanced breast cancer (ABC). J. Clin. Oncol. 2017, 34. [CrossRef]

137. Dennison, J.B.; Molina, J.R.; Mitra, S.; González-Angulo, A.M.; Balko, J.M.; Kuba, M.G.; Sanders, M.E.; Pinto, J.A.; Gómez, H.L.; Arteaga, C.L.; et al. Lactate dehydrogenase B: A metabolic marker of response to neoadjuvant chemotherapy in breast cancer. Clin. Cancer Res. 2013, 19, 3703-3713. [CrossRef]

138. Guda, M.R.; Asuthkar, S.; Labak, C.M.; Tsung, A.J.; Alexandrov, I.; Mackenzie, M.J.; Prasad, D.V.; Velpula, K.K. Targeting PDK4 inhibits breast cancer metabolism. Am. J. Cancer Res. 2018, 8, 1725-1738.

139. Pelley, J.W. 6-Glycolysis and Pyruvate Oxidation. In Elsevier's Integrated Biochemistry; Pelley, J.W., Ed.; Mosby: Philadelphia, PA, USA, 2007; pp. 47-53. [CrossRef]

140. Woolbright, B.L.; Rajendran, G.; Harris, R.A.; Taylor, J.A. Metabolic Flexibility in Cancer: Targeting the Pyruvate Dehydrogenase Kinase:Pyruvate Dehydrogenase Axis. Mol. Cancer Ther. 2019, 18, 1673. [CrossRef]

141. Sradhanjali, S.; Reddy, M.M. Inhibition of Pyruvate Dehydrogenase Kinase as a Therapeutic Strategy against Cancer. Curr. Top Med. Chem. 2018, 18, 444-453. [CrossRef]

142. Peng, F.; Wang, J.H.; Fan, W.J.; Meng, Y.T.; Li, M.M.; Li, T.T.; Cui, B.; Wang, H.F.; Zhao, Y.; An, F.; et al. Glycolysis gatekeeper PDK1 reprograms breast cancer stem cells under hypoxia. Oncogene 2018, 37, 1062-1074. [CrossRef]

143. Walter, W.; Thomalla, J.; Bruhn, J.; Fagan, D.H.; Zehowski, C.; Yee, D.; Skildum, A. Altered regulation of PDK4 expression promotes antiestrogen resistance in human breast cancer cells. Springerplus 2015, 4, 689. [CrossRef] [PubMed]

144. Lu, C.-W.; Lin, S.-C.; Chien, C.-W.; Lin, S.-C.; Lee, C.-T.; Lin, B.-W.; Lee, J.-C.; Tsai, S.-J. Overexpression of pyruvate dehydrogenase kinase 3 increases drug resistance and early recurrence in colon cancer. Am. J. Pathol. 2011, 179, 1405-1414. [CrossRef] [PubMed]

145. Saunier, E.; Benelli, C.; Bortoli, S. The pyruvate dehydrogenase complex in cancer: An old metabolic gatekeeper regulated by new pathways and pharmacological agents. Int. J. Cancer 2016, 138, 809-817. [CrossRef]

146. Iorns, E.; Lord, C.J.; Ashworth, A. Parallel RNAi and compound screens identify the PDK1 pathway as a target for tamoxifen sensitization. Biochem. J. 2009, 417, 361-370. [CrossRef] [PubMed] 
147. Zhang, W.; Zhang, S.L.; Hu, X.; Tam, K.Y. Targeting Tumor Metabolism for Cancer Treatment: Is Pyruvate Dehydrogenase Kinases (PDKs) a Viable Anticancer Target? Int. J. Biol. Sci. 2015, 11, 1390-1400. [CrossRef] [PubMed]

148. Corbet, C.; Bastien, E.; Draoui, N.; Doix, B.; Mignion, L.; Jordan, B.F.; Marchand, A.; Vanherck, J.-C.; Chaltin, P.; Schakman, O.; et al. Interruption of lactate uptake by inhibiting mitochondrial pyruvate transport unravels direct antitumor and radiosensitizing effects. Nat. Commun. 2018, 9, 1208. [CrossRef] [PubMed]

149. Mustacchi, G.; De Laurentiis, M. The role of taxanes in triple-negative breast cancer: Literature review. Drug Des. Dev. Ther. 2015, 9, 4303-4318. [CrossRef]

150. O'Reilly, E.A.; Gubbins, L.; Sharma, S.; Tully, R.; Guang, M.H.Z.; Weiner-Gorzel, K.; McCaffrey, J.; Harrison, M.; Furlong, F.; Kell, M.; et al. The fate of chemoresistance in triple negative breast cancer (TNBC). BBA Clin. 2015, 3, 257-275. [CrossRef]

151. Chen, S.Y.; Hu, S.S.; Dong, Q.; Cai, J.X.; Zhang, W.P.; Sun, J.Y.; Wang, T.T.; Xie, J.; He, H.R.; Xing, J.F.; et al. Establishment of Paclitaxel-resistant Breast Cancer Cell Line and Nude Mice Models, and Underlying Multidrug Resistance Mechanisms in Vitro and in Vivo. Asian Pac. J. Cancer Prev. 2013, 14, 6135-6140. [CrossRef]

152. Němcová-Fürstová, V.; Kopperová, D.; Balušíková, K.; Ehrlichová, M.; Brynychová, V.; Václavíková, R.; Daniel, P.; Souček, P.; Kovář, J. Characterization of acquired paclitaxel resistance of breast cancer cells and involvement of ABC transporters. Toxicol. Appl. Pharmacol. 2016, 310, 215-228. [CrossRef]

153. Zajdel, A.; Wolny, D.; Kalucka-Janik, M.; Wilczok, A. Paclitaxel in breast cancer-drug resistance and strategies to counteract it. Adv. Hyg. Exp. Med. 2019, 73, 508-515. [CrossRef]

154. Nakano, A.; Tsuji, D.; Miki, H.; Cui, Q.; El Sayed, S.M.; Ikegame, A.; Oda, A.; Amou, H.; Nakamura, S.; Harada, T.; et al. Glycolysis inhibition inactivates ABC transporters to restore drug sensitivity in malignant cells. PLoS ONE 2011, 6, e27222. [CrossRef] [PubMed]

155. Zuo, K.Q.; Zhang, X.P.; Zou, J.; Li, D.; Lv, Z.W. Establishment of a Paclitaxel Resistant Human Breast Cancer Cell Strain (MCF-7/Taxol) and Intracellular Paclitaxel Binding Protein Analysis. J. Int. Med Res. 2010, 38, 1428-1435. [CrossRef] [PubMed]

156. Schittek, B. The multiple facets of dermcidin in cell survival and host defense. J. Innate Immun. 2012, 4, 349-360. [CrossRef]

157. Hadzic, T.; Aykin-Burns, N.; Zhu, Y.; Coleman, M.C.; Leick, K.; Jacobson, G.M.; Spitz, D.R. Paclitaxel combined with inhibitors of glucose and hydroperoxide metabolism enhances breast cancer cell killing via H2O2-mediated oxidative stress. Free Radic. Biol. Med. 2010, 48, 1024-1033. [CrossRef]

158. Raez, L.E.; Papadopoulos, K.; Ricart, A.D.; Chiorean, E.G.; Dipaola, R.S.; Stein, M.N.; Rocha Lima, C.M.; Schlesselman, J.J.; Tolba, K.; Langmuir, V.K.; et al. A phase I dose-escalation trial of 2-deoxy-D-glucose alone or combined with docetaxel in patients with advanced solid tumors. Cancer Chemother. Pharmacol. 2013, 71, 523-530. [CrossRef]

159. Mishra, D.; Banerjee, D. Lactate Dehydrogenases as Metabolic Links between Tumor and Stroma in the Tumor Microenvironment. Cancers 2019, 11, 750. [CrossRef]

160. El-Sisi, A.E.; Sokar, S.S.; Abu-Risha, S.E.; El-Mahrouk, S.R. Oxamate potentiates taxol chemotherapeutic efficacy in experimentally-induced solid ehrlich carcinoma (SEC) in mice. Biomed. Pharmacother. 2017, 95, 1565-1573. [CrossRef]

161. Ge, X.; Cao, Z.; Gu, Y.; Wang, F.; Li, J.; Han, M.; Xia, W.; Yu, Z.; Lyu, P. PFKFB3 potentially contributes to paclitaxel resistance in breast cancer cells through TLR4 activation by stimulating lactate production. Cell. Mol. Biol. 2016, 62, 119-125.

162. Cretella, D.; Fumarola, C.; Bonelli, M.; Alfieri, R.; La Monica, S.; Digiacomo, G.; Cavazzoni, A.; Galetti, M.; Generali, D.; Petronini, P.G. Pre-treatment with the CDK4/6 inhibitor palbociclib improves the efficacy of paclitaxel in TNBC cells. Sci. Rep. 2019, 9, 13014. [CrossRef]

163. El Sayed, R.; El Jamal, L.; El Iskandarani, S.; Kort, J.; Abdel Salam, M.; Assi, H. Endocrine and Targeted Therapy for Hormone-Receptor-Positive, HER2-Negative Advanced Breast Cancer: Insights to Sequencing Treatment and Overcoming Resistance Based on Clinical Trials. Front. Oncol. 2019, 9, 510. [CrossRef] [PubMed]

164. Zhou, X.; Chen, R.; Yu, Z.; Li, R.; Li, J.; Zhao, X.; Song, S.; Liu, J.; Huang, G. Dichloroacetate restores drug sensitivity in paclitaxel-resistant cells by inducing citric acid accumulation. Mol. Cancer 2015, 14, 63. [CrossRef] [PubMed] 
165. Cuello-Carrión, F.D.; Shortrede, J.E.; Alvarez-Olmedo, D.; Cayado-Gutiérrez, N.; Castro, G.N.; Zoppino, F.C.M.; Guerrero, M.; Martinis, E.; Wuilloud, R.; Gómez, N.N.; et al. HER2 and $\beta$-catenin protein location: Importance in the prognosis of breast cancer patients and their correlation when breast cancer cells suffer stressful situations. Clin. Exp. Metastasis 2015, 32, 151-168. [CrossRef] [PubMed]

166. El-Sahli, S.; Xie, Y.; Wang, L.; Liu, S. Wnt Signaling in Cancer Metabolism and Immunity. Cancers 2019, 11, 904. [CrossRef] [PubMed]

167. Gupta, N.; Gupta, P.; Srivastava, S.K. Penfluridol overcomes paclitaxel resistance in metastatic breast cancer. Sci. Rep. 2019, 9, 5066. [CrossRef]

168. Xiang, F.; Fan, Y.; Ni, Z.; Liu, Q.; Zhu, Z.; Chen, Z.; Hao, W.; Yue, H.; Wu, R.; Kang, X. Ursolic Acid Reverses the Chemoresistance of Breast Cancer Cells to Paclitaxel by Targeting MiRNA-149-5p/MyD88. Front. Oncol. 2019, 9, 501. [CrossRef]

169. Guan, D.G.; Chen, H.M.; Liao, S.F.; Zhao, T.Z. Combination of temozolomide and Taxol exerts a synergistic inhibitory effect on Taxolresistant glioma cells via inhibition of glucose metabolism. Mol. Med. Rep. 2015, 12, 7705-7711. [CrossRef]

170. Garon, E.B.; Christofk, H.R.; Hosmer, W.; Britten, C.D.; Bahng, A.; Crabtree, M.J.; Hong, C.S.; Kamranpour, N.; Pitts, S.; Kabbinavar, F.; et al. Dichloroacetate should be considered with platinum-based chemotherapy in hypoxic tumors rather than as a single agent in advanced non-small cell lung cancer. J. Cancer Res. Clin. Oncol. 2014, 140, 443-452. [CrossRef]

171. García-Castillo, V.; López-Urrutia, E.; Villanueva-Sánchez, O.; Ávila-Rodríguez, M.Á.; Zentella-Dehesa, A.; Cortés-González, C.; López-Camarillo, C.; Jacobo-Herrera, N.J.; Pérez-Plasencia, C. Targeting Metabolic Remodeling in Triple Negative Breast Cancer in a Murine Model. J. Cancer 2017, 8, 178-189. [CrossRef]

172. Amadori, D.; Frassineti, G.L.; De Matteis, A.; Mustacchi, G.; Santoro, A.; Cariello, S.; Ferrari, M.; Nascimben, O.; Nanni, O.; Lombardi, A.; et al. Modulating effect of lonidamine on response to doxorubicin in metastatic breast cancer patients: Results from a multicenter prospective randomized trial. Breast Cancer Res. Treat. 1998, 49, 209-217. [CrossRef]

173. Attia, Y.M.; El-Abhar, H.S.; Al Marzabani, M.M.; Shouman, S.A. Targeting glycolysis by 3-bromopyruvate improves tamoxifen cytotoxicity of breast cancer cell lines. BMC Cancer 2015, 15, 838. [CrossRef] [PubMed]

174. Cufi, S.; Corominas-Faja, B.; Vazquez-Martin, A.; Oliveras-Ferraros, C.; Dorca, J.; Bosch-Barrera, J.; Martin-Castillo, B.; Menendez, J.A. Metformin-induced preferential killing of breast cancer initiating CD44+CD24-/low cells is sufficient to overcome primary resistance to trastuzumab in HER2+ human breast cancer xenografts. Oncotarget 2012, 3, 395-398. [CrossRef]

175. Martin-Castillo, B.; Dorca, J.; Vazquez-Martin, A.; Oliveras-Ferraros, C.; Lopez-Bonet, E.; Garcia, M.; Del Barco, S.; Menendez, J.A. Incorporating the antidiabetic drug metformin in HER2-positive breast cancer treated with neo-adjuvant chemotherapy and trastuzumab: An ongoing clinical-translational research experience at the Catalan Institute of Oncology. Ann. Oncol. 2010, 21, 187-189. [CrossRef]

176. Dasari, S.; Tchounwou, P.B. Cisplatin in cancer therapy: Molecular mechanisms of action. Eur. J. Pharmacol. 2014, 740, 364-378. [CrossRef]

177. Florea, A.-M.; Büsselberg, D. Cisplatin as an anti-tumor drug: Cellular mechanisms of activity, drug resistance and induced side effects. Cancers 2011, 3, 1351-1371. [CrossRef] [PubMed]

178. Siddik, Z.H. Cisplatin: Mode of cytotoxic action and molecular basis of resistance. Oncogene 2003, 22, 7265-7279. [CrossRef] [PubMed]

179. Zaal, E.A.; Berkers, C.R. The Influence of Metabolism on Drug Response in Cancer. Front. Oncol. 2018, 8, 500. [CrossRef]

180. Egawa-Takata, T.; Endo, H.; Fujita, M.; Ueda, Y.; Miyatake, T.; Okuyama, H.; Yoshino, K.; Kamiura, S.; Enomoto, T.; Kimura, T.; et al. Early reduction of glucose uptake after cisplatin treatment is a marker of cisplatin sensitivity in ovarian cancer. Cancer Sci. 2010, 101, 2171-2178. [CrossRef]

181. Dhar, S.; Lippard, S.J. Mitaplatin, a potent fusion of cisplatin and the orphan drug dichloroacetate. Proc. Natl. Acad. Sci. USA 2009, 106, 22199-22204. [CrossRef]

182. Gang, B.P.; Dilda, P.J.; Hogg, P.J.; Blackburn, A.C. Targeting of two aspects of metabolism in breast cancer treatment. Cancer Biol. Ther. 2014, 15, 1533-1541. [CrossRef]

183. Lee, J.O.; Kang, M.J.; Byun, W.S.; Kim, S.A.; Seo, I.H.; Han, J.A.; Moon, J.W.; Kim, J.H.; Kim, S.J.; Lee, E.J.; et al. Metformin overcomes resistance to cisplatin in triple-negative breast cancer (TNBC) cells by targeting RAD51. Breast Cancer Res. 2019, 21, 115. [CrossRef] [PubMed] 
184. Criscitiello, C.; Fumagalli, D.; Saini, K.S.; Loi, S. Tamoxifen in early-stage estrogen receptor-positive breast cancer: Overview of clinical use and molecular biomarkers for patient selection. Onco Targets Ther. 2010, 4, 1-11. [CrossRef] [PubMed]

185. Chang, M. Tamoxifen resistance in breast cancer. Biomol. Ther. 2012, 20, 256-267. [CrossRef] [PubMed]

186. An, K.-C. Selective Estrogen Receptor Modulators. Asian Spine J. 2016, 10, 787-791. [CrossRef] [PubMed]

187. Woo, S.H.; Seo, S.K.; Park, Y.; Kim, E.K.; Seong, M.K.; Kim, H.A.; Song, J.Y.; Hwang, S.G.; Lee, J.K.; Noh, W.C.; et al. Dichloroacetate potentiates tamoxifen-induced cell death in breast cancer cells via downregulation of the epidermal growth factor receptor. Oncotarget 2016, 7, 59809-59819. [CrossRef]

188. Manna, S.; Holz, M.K. Tamoxifen Action in ER-Negative Breast Cancer. Signal Transduct. Insights 2016, 5, 1-7. [CrossRef]

189. Daurio, N.A. Tamoxifen Mediated Metabolic Stress: Molecular Mechanism and Therapeutic Opportunities. Ph.D. Thesis, University of Pennsylvania, Philadelphia, PA, USA, 2016.

190. Mayer, I. Role of mTOR inhibition in preventing resistance and restoring sensitivity to hormone-targeted and HER2-targeted therapies in breast cancer. Clin. Adv. Hematol. Oncol. 2013, 11, 217-224.

191. Ferrari, P.; Nicolini, A. Chapter 29-Overcoming Endocrine Resistance in Breast Cancer: mTOR Inhibitors and New Drugs. In Oncogenomics; Dammacco, F., Silvestris, F., Eds.; Academic Press: Cambridge, MA, USA, 2019; pp. 393-422. [CrossRef]

192. Lovitt, C.J.; Shelper, T.B.; Avery, V.M. Doxorubicin resistance in breast cancer cells is mediated by extracellular matrix proteins. BMC Cancer 2018, 18, 41. [CrossRef]

193. Smith, L.; Watson, M.B.; Kane, S.L.; Drew, P.J.; Lind, M.J.; Cawkwell, L. The analysis of doxorubicin resistance in human breast cancer cells using antibody microarrays. Mol. Cancer Ther. 2006, 5, 2115. [CrossRef]

194. Lin, J.H.; Yamazaki, M. Clinical Relevance of P-Glycoprotein in Drug Therapy. Drug Metab. Rev. 2003, 35, 417-454. [CrossRef]

195. Jones, P.M.; George, A.M. The ABC transporter structure and mechanism: Perspectives on recent research. Cell. Mol. Life Sci. CMLS 2004, 61, 682-699. [CrossRef] [PubMed]

196. Bean, J.F.; Qiu, Y.-Y.; Yu, S.; Clark, S.; Chu, F.; Madonna, M.B. Glycolysis inhibition and its effect in doxorubicin resistance in neuroblastoma. J. Pediatr. Surg. 2014, 49, 981-984. [CrossRef] [PubMed]

197. Moldogazieva, N.T.; Mokhosoev, I.M.; Terentiev, A.A. Metabolic Heterogeneity of Cancer Cells: An Interplay between HIF-1, GLUTs, and AMPK. Cancers 2020, 12, 862. [CrossRef] [PubMed]

198. Wang, L.; Chan, J.Y.; Zhou, X.; Cui, G.; Yan, Z.; Wang, L.; Yan, R.; Di, L.; Wang, Y.; Hoi, M.P.; et al. A Novel Agent Enhances the Chemotherapeutic Efficacy of Doxorubicin in MCF-7 Breast Cancer Cells. Front. Pharmacol. 2016, 7, 249. [CrossRef]

199. Zong, L.; Cheng, G.; Liu, S.; Pi, Z.; Liu, Z.; Song, F. Reversal of multidrug resistance in breast cancer cells by a combination of ursolic acid with doxorubicin. J. Pharm. Biomed. Anal. 2019, 165, 268-275. [CrossRef]

200. Xu, M.; Chen, S.; Yang, W.; Cheng, X.; Ye, Y.; Mao, J.; Wu, X.; Huang, L.; Ji, J. FGFR4 Links Glucose Metabolism and Chemotherapy Resistance in Breast Cancer. Cell. Physiol. Biochem. 2018, 47, 151-160. [CrossRef]

201. Qu, C.; Zhang, W.; Zheng, G.; Zhang, Z.; Yin, J.; He, Z. Metformin reverses multidrug resistance and epithelial-mesenchymal transition (EMT) via activating AMP-activated protein kinase (AMPK) in human breast cancer cells. Mol. Cell. Biochem. 2014, 386, 63-71. [CrossRef]

202. Marinello, P.C.; Panis, C.; Silva, T.N.X.; Binato, R.; Abdelhay, E.; Rodrigues, J.A.; Mencalha, A.L.; Lopes, N.M.D.; Luiz, R.C.; Cecchini, R.; et al. Metformin prevention of doxorubicin resistance in MCF-7 and MDA-MB-231 involves oxidative stress generation and modulation of cell adaptation genes. Sci. Rep. 2019, 9, 5864. [CrossRef]

203. Hoxhaj, G.; Manning, B.D. The PI3K-AKT network at the interface of oncogenic signalling and cancer metabolism. Nat. Rev. Cancer 2020, 20, 74-88. [CrossRef]

204. Zhao, Y.; Liu, H.; Liu, Z.; Ding, Y.; LeDoux, S.P.; Wilson, G.L.; Voellmy, R.; Lin, Y.; Lin, W.; Nahta, R.; et al. Overcoming Trastuzumab Resistance in Breast Cancer by Targeting Dysregulated Glucose Metabolism. Cancer Res. 2011, 71, 4585. [CrossRef]

205. Junttila, T.T.; Akita, R.W.; Parsons, K.; Fields, C.; Lewis Phillips, G.D.; Friedman, L.S.; Sampath, D.; Sliwkowski, M.X. Ligand-independent HER2/HER3/PI3K complex is disrupted by trastuzumab and is effectively inhibited by the PI3K inhibitor GDC-0941. Cancer Cell 2009, 15, 429-440. [CrossRef] [PubMed] 
206. Hoopmann, M.; Warm, M.; Mallmann, P.; Thomas, A.; Göhring, U.J.; Schöndorf, T. Tumor M2 pyruvate kinase-Determination in breast cancer patients receiving trastuzumab therapy. Cancer Lett. 2002, 187, 223-228. [CrossRef]

207. Pelicano, H.; Martin, D.S.; Xu, R.H.; Huang, P. Glycolysis inhibition for anticancer treatment. Oncogene 2006, 25, 4633-4646. [CrossRef] [PubMed]

208. Morikawa, A.; Henry, N.L. Palbociclib for the Treatment of Estrogen Receptor-Positive, HER2-Negative Metastatic Breast Cancer. Clin. Cancer Res. 2015, 21, 3591. [CrossRef] [PubMed]

209. Lorito, N.; Bacci, M.; Smiriglia, A.; Mannelli, M.; Parri, M.; Comito, G.; Ippolito, L.; Giannoni, E.; Bonechi, M.; Benelli, M.; et al. Glucose Metabolic Reprogramming of ER Breast Cancer in Acquired Resistance to the CDK4/6 Inhibitor Palbociclib+. Cells 2020, 9, 668. [CrossRef] [PubMed]

210. Strickaert, A.; Saiselet, M.; Dom, G.; De Deken, X.; Dumont, J.E.; Feron, O.; Sonveaux, P.; Maenhaut, C. Cancer heterogeneity is not compatible with one unique cancer cell metabolic map. Oncogene 2017, 36, 2637-2642. [CrossRef]

211. Heaster, T.M.; Landman, B.A.; Skala, M.C. Quantitative Spatial Analysis of Metabolic Heterogeneity across in vivo and in vitro Tumor Models. Front. Oncol. 2019, 9, 1144. [CrossRef]

212. Ciavardelli, D.; Rossi, C.; Barcaroli, D.; Volpe, S.; Consalvo, A.; Zucchelli, M.; De Cola, A.; Scavo, E.; Carollo, R.; D'Agostino, D.; et al. Breast cancer stem cells rely on fermentative glycolysis and are sensitive to 2-deoxyglucose treatment. Cell Death Dis. 2014, 5, e1336. [CrossRef]

213. Chen, F.; Chen, J.; Yang, L.; Liu, J.; Zhang, X.; Zhang, Y.; Tu, Q.; Yin, D.; Lin, D.; Wong, P.P.; et al. Extracellular vesicle-packaged HIF-1 $\alpha$-stabilizing lncRNA from tumour-associated macrophages regulates aerobic glycolysis of breast cancer cells. Nat. Cell Biol. 2019, 21, 498-510. [CrossRef]

214. Snaebjornsson, M.T.; Schulze, A. Non-canonical functions of enzymes facilitate cross-talk between cell metabolic and regulatory pathways. Exp. Mol. Med. 2018, 50,34. [CrossRef]

215. Denko, N.C. Hypoxia, HIF1 and glucose metabolism in the solid tumour. Nat. Rev. Cancer 2008, 8, 705-713. [CrossRef] [PubMed]

216. Gonzalez-Angulo, A.M.; Blumenschein, G.R., Jr. Defining biomarkers to predict sensitivity to PI3K/Akt/mTOR pathway inhibitors in breast cancer. Cancer Treat. Rev. 2013, 39, 313-320. [CrossRef] [PubMed]

217. Varghese, E.; Liskova, A.; Kubatka, P.; Mathews Samuel, S.; Busselberg, D. Anti-Angiogenic Effects of Phytochemicals on miRNA Regulating Breast Cancer Progression. Biomolecules 2020, 10, 191. [CrossRef] [PubMed]

218. Huang, W.-C.; Hung, M.-C. Induction of Akt Activity by Chemotherapy Confers Acquired Resistance. J. Formos. Med Assoc. 2009, 108, 180-194. [CrossRef]

219. Agrawal, S.; Łuc, M.; Ziółkowski, P.; Agrawal, A.K.; Pielka, E.; Walaszek, K.; Zduniak, K.; Woźniak, M. Insulin-induced enhancement of MCF-7 breast cancer cell response to 5-fluorouracil and cyclophosphamide. Tumor Biol. 2017, 39, 1010428317702901. [CrossRef] [PubMed]

220. Lasalvia-Prisco, E.; Cucchi, S.; Vázquez, J.; Lasalvia-Galante, E.; Golomar, W.; Gordon, W. Insulin-induced enhancement of antitumoral response to methotrexate in breast cancer patients. Cancer Chemother. Pharmacol. 2004, 53, 220-224. [CrossRef]

221. Zhou, P.; Bogacki, R.; McReynolds, L.; Howley, P.M. Harnessing the ubiquitination machinery to target the degradation of specific cellular proteins. Mol. Cell 2000, 6, 751-756. [CrossRef]

222. Rodriguez-Gonzalez, A.; Cyrus, K.; Salcius, M.; Kim, K.; Crews, C.M.; Deshaies, R.J.; Sakamoto, K.M. Targeting steroid hormone receptors for ubiquitination and degradation in breast and prostate cancer. Oncogene 2008, 27, 7201-7211. [CrossRef]

223. Barbosa, A.M.; Martel, F. Targeting Glucose Transporters for Breast Cancer Therapy: The Effect of Natural and Synthetic Compounds. Cancers 2020, 12, 154. [CrossRef]

224. Calvaresi, E.C.; Hergenrother, P.J. Glucose conjugation for the specific targeting and treatment of cancer. Chem. Sci. 2013, 4, 2319-2333. [CrossRef]

225. Miskimins, W.K.; Ahn, H.J.; Kim, J.Y.; Ryu, S.; Jung, Y.-S.; Choi, J.Y. Synergistic Anti-Cancer Effect of Phenformin and Oxamate. PLoS ONE 2014, 9, e85576. [CrossRef] [PubMed]

226. Zhang, D.; Wang, H.; Yu, W.; Qiao, F.; Su, X.; Xu, H. Downregulation of hexokinase 2 improves radiosensitivity of breast cancer. Transl. Cancer Res. 2019, 8, 290-297. [CrossRef] 
227. Lanning, N.J.; Castle, J.P.; Singh, S.J.; Leon, A.N.; Tovar, E.A.; Sanghera, A.; MacKeigan, J.P.; Filipp, F.V.; Graveel, C.R. Metabolic profiling of triple-negative breast cancer cells reveals metabolic vulnerabilities. Cancer Metab. 2017, 5, 6. [CrossRef] [PubMed]

228. Phan, L.M.; Yeung, S.-C.J.; Lee, M.-H. Cancer metabolic reprogramming: Importance, main features, and potentials for precise targeted anti-cancer therapies. Cancer Biol. Med. 2014, 11, 1-19. [CrossRef] [PubMed]

229. Prieto-Vila, M.; Takahashi, R.-U.; Usuba, W.; Kohama, I.; Ochiya, T. Drug Resistance Driven by Cancer Stem Cells and Their Niche. Int. J. Mol. Sci. 2017, 18, 2574. [CrossRef] [PubMed]

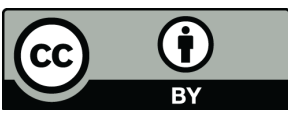

(C) 2020 by the authors. Licensee MDPI, Basel, Switzerland. This article is an open access article distributed under the terms and conditions of the Creative Commons Attribution (CC BY) license (http://creativecommons.org/licenses/by/4.0/). 